\title{
3D printed silica-gelatin hybrid scaffolds of specific channel sizes promote collagen type II, Sox9 and Aggrecan production from chondrocytes
}

\author{
Maria Nelson ${ }^{1}$, Siwei $\mathrm{Li}^{1}$, Samuel J. Page ${ }^{2}$, Xiaomeng Shi ${ }^{1}$, Peter D. Lee ${ }^{3}$, Molly M. \\ Stevens ${ }^{1,4,5}$, John V. Hanna ${ }^{2}$, Julian R. Jones ${ }^{1}$ \\ ${ }^{1}$ Department of Materials, Imperial College London, London, SW7 2AZ, UK \\ ${ }^{2}$ Department of Physics, University of Warwick, Gibbet Hill Road, Coventry CV4 7AL, UK \\ ${ }^{3}$ School of Materials, University of Manchester, Manchester, M13 9PL, UK \\ ${ }^{4}$ Institute of Biomedical Engineering Imperial College London, London, SW7 2AZ, UK \\ ${ }^{5}$ Department of Bioengineering Imperial College London, London, SW7 2AZ, UK.
}

\begin{abstract}
Inorganic/organic hybrids have co-networks of inorganic and organic components, with the aim of obtaining synergy of the properties of those components. Here, a silica-gelatin sol-gel hybrid "ink" was directly 3D printed to produce 3D grid-like scaffolds, using a coupling agent, 3-glycidyloxypropyl)trimethoxysilane (GPTMS), to form covalent bonds between the silicate and gelatin co-networks. Scaffolds were printed with $1 \mathrm{~mm}$ strut separation, but the drying method affected the final architecture and properties. Freeze drying produced $<40 \mu \mathrm{m}$ struts and large $\sim 700 \mu \mathrm{m}$ channels. Critical point drying enabled strut consolidation and optimal mechanical properties, with $\sim 160 \mu \mathrm{m}$ struts and $\sim 200 \mu \mathrm{m}$ channels, which improved mechanical properties. This architecture was critical to cellular response: when chondrocytes were seeded on the scaffolds with $200 \mu \mathrm{m}$ wide pore channels in vitro, collagen Type II matrix was preferentially produced (negligible amount of Type I or X were observed), indicative of hyaline-like cartilaginous matrix formation, but when pore channels were 700 $\mu \mathrm{m}$ wide, Type I collagen was prevalent. This was supported by Sox9 and Aggrecan expression. The scaffolds have potential for regeneration of articular cartilage regeneration, particularly in sports medicine cases.
\end{abstract}

Keywords: 3D printing; hybrid; articular cartilage; scaffold.

\section{Introduction}

Articular cartilage defects affect millions of people worldwide and treatment is currently limited to replacement with synthetic materials or regeneration through stimulation of fibrocartilage growth, e.g. via microfracture surgery ${ }^{1}$. Neither strategy restores the structure, properties nor function of hyaline articular cartilage as it has limited self-repair due to low cell density, low metabolism and absence of blood supply ${ }^{2}$. In young people, most joint problems begin with small lesions in the articular cartilage tissue due to wear and tear, trauma or sporting injures ${ }^{3}$. If the lesion is detected and surround by otherwise healthy cartilage, microfracture (or nanofracture) can be performed, in which small holes are made in 
the subchondral bone to enable bone marrow to fill the defect, enabling some progenitor/stem cells to reach the defect site ${ }^{4}$. However, due to low numbers of progenitor cells in a heterogeneous population and lack of organisation, fibrocartilage results. With inferior mechanical and structural properties compared to hyaline cartilage, the repair tissue cannot sustain the loads of the articular joint and degeneration occurs, requiring repetition of the surgery ${ }^{1}$.

Autologous matrix-induced chondrogenesis (AMIC) is a one-step approach that combines microfracture with a scaffold ${ }^{5}$. This type of approach has potential if the scaffold can promote Type II collagen matrix production and share load with the host cartilage. Currently, layered fibremat-like porcine collagen scaffolds, e.g. Chondro-Gide ${ }^{\circledR}$ (Geistlich Biomaterials, Switzerland), are used in the AMIC technique ${ }^{6}$, but while some Type II collagen matrix was detected, clinical outcomes have been similar to microfracture without the scaffold ${ }^{7}$. Although clinical studies report positive patient ${ }^{8}$, long term success of such material remains in doubt due the type of cartilage formed. Hydrogels have been used in modified AMIC animal studies ${ }^{9}$, but they have low mechanical properties ${ }^{10}$.

One strategy for improving the quality of articular cartilage regeneration is to develop a scaffold that has potential to modify the AMIC technique and regenerate full-thickness cartilage defects. In a modified procedure, a scaffold should provide a suitable environment for bone marrow stromal cells (MSCs) to become chondrogenic and produce hyaline cartilage extracellular matrix. The scaffold should have a stiffness conducive to cartilage formation and a similar response to mechanical loads as cartilage before degrading/ remodelling as the native tissue structure develops ${ }^{11-13}$. The Chondro-Gide ${ }^{\circledR}$ scaffold has shown some success ${ }^{9}$, but could be improved by tailored stiffness and pore architecture. The 3D pore architecture present within scaffolds used for cartilage tissue engineering also plays a vital role in tissue formation ${ }^{13,14}$. For example, efficient diffusion channels across a scaffold are essential to allow for full thickness infiltration of cells and extracellular matrix formation while avoiding waste build-up ${ }^{15}$.

3D printing can provide accurate control over scaffold design. Printed scaffolds have been predominantly synthetic biodegradable polymers, such as poly(L-lactide), due to ease of 3D printing but they do not have suitable surface chemistry, stiffness or biodegradation rate ${ }^{16}$. New "inks" are required. The collagen used to produce Chondro-Gide ${ }^{\circledR}$ is difficult to print due to its low solubility ${ }^{17}$. Gelatin is a hydrolysed form of collagen and retains the information signals that may promote cell differentiation, e.g. the Arg-Gly-Asp (RGD) sequences ${ }^{18}$. However, scaffolds made of gelatin alone have poor mechanical properties, an order of magnitude lower than native cartilage, even when crosslinked in a dual network ${ }^{19}$. To stiffen 
gelatin, silica-gelatin hybrid foam scaffolds were developed by Mahony et al. ${ }^{20,21}$. Sol-gel hybrids are co-networks of inorganic (e.g. silica) and organic (in this case gelatin), wherein the molecular level interactions enable them to retain strength from the inorganic and elasticity from the organic ${ }^{22}$. Mechanical properties and dissolution of the foam hybrids were tailored through covalent coupling between the inorganic and organic networks using 3glycidyloxypropyl)trimethoxysilane (GPTMS), creating Class II hybrids ${ }^{20,21}$. Without such bonding, hybrids would dissociate rapidly on contact with water ${ }^{23}$. Silica/gelatin hybrids have also been produced as aerogels ${ }^{24,25}$ and Blaker et al. produced fibrous silica/gelatin Class II scaffolds using a solution blow spinning technique, which gave precise control over fibre diameter ${ }^{26}$. Silica/gelatin scaffolds have been printed before ${ }^{27}$, but covalent coupling, via 1ethyl-(3-3-dimethylaminopropyl) carbodiimide hydrochloride (EDC) and N-hydroxysuccinimide (NHS), was not proven to be successful (little change in mechanical properties), with the hybrids either dissolving rapidly in simulated body fluids or the dissolution was not reported. Application to cartilage regeneration was also not investigated.

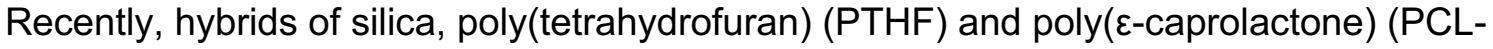
$\mathrm{diCOOH})^{28}$, were 3D printed and in vitro cultures of ATDC5 murine chondrogenic cells in scaffolds with $\sim 250 \mu \mathrm{m}$ channel size produced collagen type II matrix, with negligible collagen type I or X produced. Scaffolds made solely of PCL with similar pore architectures did not provoke collagen Type II production. Similar results were seen with the more clinically relevant human stem cells, which differentiated down a chondrocytic route when cultured on the hybrid scaffolds with $\sim 250 \mu \mathrm{m}$ channel size, with Sox9, collagen Type II, and glucosaminoglycan (GAG) production ${ }^{29}$, whereas large pores seemed to produce fibroblastic cells and collagen Type I matrix.

The aim here was to 3D print the first silica-gelatin hybrid with covalent coupling between the gelatin and silica network, and to investigate the effect of the degree of coupling and drying method (freeze drying versus critical point drying) on the architecture, structure and properties of the scaffolds. The potential of scaffold architectures for hyaline cartilaginous matrix productionin vitro, particularly the effect of pore channel size, was assessed in culture with cartilage cells.

\section{Materials and methods}

\subsection{Hybrid preparation}

All reagents were supplied by Sigma Aldrich (Dorset, UK), unless otherwise specified. Hybrid preparation was modified (Figure 1a) from the procedure developed by Mahony et al. ${ }^{20}$, 
which used hydrofluoric acid (HF) catalysis to induce rapid condensation of the silica network to produce foam scaffolds. Here, a HF-free method with a slower condensation rate was required to allow 3D printing directly from sol. Initially gelatin (Bovine, Type A) was dissolved in $10 \mathrm{mM}$ hydrochloric acid $(\mathrm{HCl})$ at a concentration of $50 \mathrm{mg} \mathrm{mL}^{-1}$. This solution was functionalised by addition of an appropriate amount of GPTMS to give molar ratios of GPTMS:gelatin (termed coupling factor, CF) ranging between 0-1000. The functionalised gelatin solution was left to mix ( $3 \mathrm{~h}$ or $14 \mathrm{~h}$ ) before being added to the sol.

A sol was prepared by adding the following in order: deionised water, $\mathrm{HCl}(1 \mathrm{M})$ and tetraethyl orthosilicate (TEOS). The molar ratio of water: TEOS (R ratio) was 4 and $\mathrm{HCl}$ was added to catalyse TEOS hydrolysis at a volume ratio (water: $\mathrm{HCl}$ ) of 3 . The solution was stirred to allow hydrolysis of TEOS $(1 \mathrm{~h})$, before adding the functionalised gelatin. The gelatin:silica ratio, e.g. $70 \mathrm{G}: 30 \mathrm{SiO}_{2},(70 \mathrm{G})$ describes the mass ratio of dry gelatin to $\mathrm{SiO}_{2}$, under the assumption that 1 mole of TEOS forms 1 mole of $\mathrm{SiO}_{2}$. Any silica contributions from GPTMS were ignored in this nominal ratio. Here, 60G, 70G, 78G and 84G compositions were investigated.

The functionalised gelatin and sol were monitored during mixing to assess printability of the hybrid inks. Some hybrids were prepared as monoliths by transferring the sol to moulds after $5 \mathrm{~h}$ mixing for further condensation of the silica network. The hybrid inks prepared for 3D printing were aged until the gels had adequate gel strength then 3D printed into scaffolds and aged. Hybrid monoliths and scaffolds were aged for 1 week and then dried by freeze drying or critical point drying.

The variables investigated to determine a new hybrid method and composition compatible with 3D printing were: CF (0-1000), functionalisation time ( $3 \mathrm{~h}$ or $14 \mathrm{~h})$, sol aging temperature $\left(21^{\circ} \mathrm{C}, 40^{\circ} \mathrm{C}\right)$, gelatin:silica ratio (60G-84G) and drying method (freeze drying or critical point drying).

Two drying methods were compared: freeze drying (FD), where samples were frozen at $-18^{\circ} \mathrm{C}$ overnight then placed in a freeze dryer (Thermo Scientific Heto PowerDry LL1500) for $24 \mathrm{~h}$ at $-96^{\circ} \mathrm{C}$ at a pressure of 0.13 mbar; critical point drying (CPD), where scaffolds were soaked at $3 \mathrm{~h}$ intervals in water-ethanol co-solvents with 10\%-100\% ethanol volume at $10 \%$ increments before the scaffolds were immersed in $100 \%$ ethanol overnight. The CPD (Tousimis 931 Series, 2.5 in I.D Chamber) was used in $8 \mathrm{~h}$ Stasis Mode. The critical point is achieved at a critical temperature and pressure of $31^{\circ} \mathrm{C}$ and $1072 \mathrm{psi} / 173.9$ bar for 2 minutes. 


\subsection{Verification of covalent coupling}

The ninhydrin assay was used to determine the efficiency of the GPTMS coupling, and the degree of crosslinking in the hybrid, as it can quantify the number of primary and secondary amine units in a solution, which here would correspond to dissolved, uncoupled gelatin ${ }^{30} .2$ $\mathrm{mL}$ of $\mathrm{DI}$ water was added to hybrid samples and gelatin standards in glass vials and held in a water bath for $1 \mathrm{~h}$ at $80^{\circ} \mathrm{C}$, when $1 \mathrm{~mL}$ of ninhydrin reagent was added to each vial and left for 30 minutes. The samples and standards were cooled to room temperature and $5 \mathrm{~mL}$ of $95 \%$ ethanol added. A further dilution of 1:49 sample/standard volume to additional ethanol volume was required. Absorbance values were measured using a microplate reader (SpectraMax M5) at $570 \mathrm{~nm}$ from a 48 well plate. From the calibration curve, the presence of free amino acids and hence unreacted gelatin was quantified. To calculate the crosslinking index (the degree of crosslinking in the hybrid),

Eq. 1 was used, where respectively; $C_{i}$ and $C$ are the optical absorbance of the gelatin solution before and after cross-linking.

$$
\text { Crosslinking Index }(\%)=\frac{C_{i}+C}{C_{i}} \times 100
$$

Solid state ${ }^{29} \mathrm{Si}$ MAS NMR measurements were performed at 7.0 T using a Bruker HD-300 spectrometer operating at a Larmor frequency of $69.62 \mathrm{MHz}$. These experiments were performed using a Bruker $7 \mathrm{~mm} \mathrm{HX}$ probe which enabled a MAS frequency of $5 \mathrm{kHz}$ to be implemented. Quantitatively reliable ${ }^{29} \mathrm{Si}$ MAS NMR data were acquired through the use of single pulse excitation experiments with ${ }^{1} \mathrm{H}$ decoupling during data acquisition. $\mathrm{A}^{29} \mathrm{Si} \pi / 2$ pulse time of $5.5 \mu \mathrm{s}$ was calibrated on solid kaolinite and all experiments employed $\pi / 4$ pulse time of $2.75 \mu \mathrm{s}$, long recycle delays of $240 \mathrm{~s}$, and a ${ }^{1} \mathrm{H}$ decoupling field of $\sim 80 \mathrm{kHz}$ during FID acquisition. Each ${ }^{29} \mathrm{Si}$ chemical shift was referenced to TMS ( $\left.\delta 0.0 \mathrm{ppm}\right)$ via the secondary solid kaolinite reference $(\delta-92 \mathrm{ppm})$. The simulation, deconvolution and measurement of the relative resonance intensities from each spectrum was undertaken using the OriginPro software package and the network condensation was calculated according to Equation $2{ }^{31}$ :

$$
D_{c}=\frac{T^{1}+2 T^{2}+3 T^{3}}{3}+\frac{2 Q^{2}+3 Q^{3}+4 Q^{4}}{4}
$$

where $Q^{n}$ is the abundance of $Q^{n}$ species and $T^{n}$ is the abundance of $T^{n}$ species. $A T^{n}$ species consists of a $\mathrm{Si}$ atom with one $\mathrm{Si}-\mathrm{C}$ bond and $\mathrm{n}$ bridging oxygen (-Si-O-Si-) bonds and 3-n non-bridging oxygen bonds. $A Q^{n}$ species consists of a Si atom with $n$ bridging oxygen bonds and 4-n non-bridging oxygen bonds. 
Thermal gravimetric analysis (TGA) was carried out on a Netzsch (Selb, Germany) STA $449 \mathrm{C}$ between $21^{\circ} \mathrm{C}$ and $800^{\circ} \mathrm{C}$, ramp rate of $10 \mathrm{~K} \mathrm{~min}^{-1}$, air flow rate $50 \mathrm{~mL} \mathrm{~min}^{-1}$, in an alumina crucible $(n=3)$.

\subsection{Developing hybrid 3D printing inks}

The printing process was developed by adapting an Ultimaker Original (Ultimaker, The Netherlands) (Figure 1b). The filament reel was removed and a $10 \mathrm{~mL}$ Luer lock BD Plastipak $^{\mathrm{TM}}$ syringes with tapered printing tips attached to the printing head. Gels were held in the syringe and the deposition rate $\left(0.1 \mathrm{~mL} \mathrm{~min}^{-1}\right)$ was controlled by a PHD Ultra syringe pump (Harvard Apparatus, Holliston, MA). A $40{ }^{\circ} \mathrm{C}$ heater was placed around the syringe to ensure the gelatin component did not transition from liquid to solid prior to printing. From the syringe, the hybrid flowed along tubing (Harvard Apparatus PolyE polyethylene tubing with ID of $1.78 \mathrm{~mm}$ ) towards the printing tip. A stainless steel dispensing tip (Nordson EFD, OD $1.83 \mathrm{~mm}$ ) connected the syringe to the tubing and Ibidi male Luer connectors connected the tubing to the tapered printing tip (Nordson EFD ID $0.2 \mathrm{~mm}$ ), which was attached to the 3D printer. The printing parameters were: $1 \mathrm{~mm}$ strut separation, $0.3 \mathrm{~mm}$ layer height, print head speed of 500 feed rate.

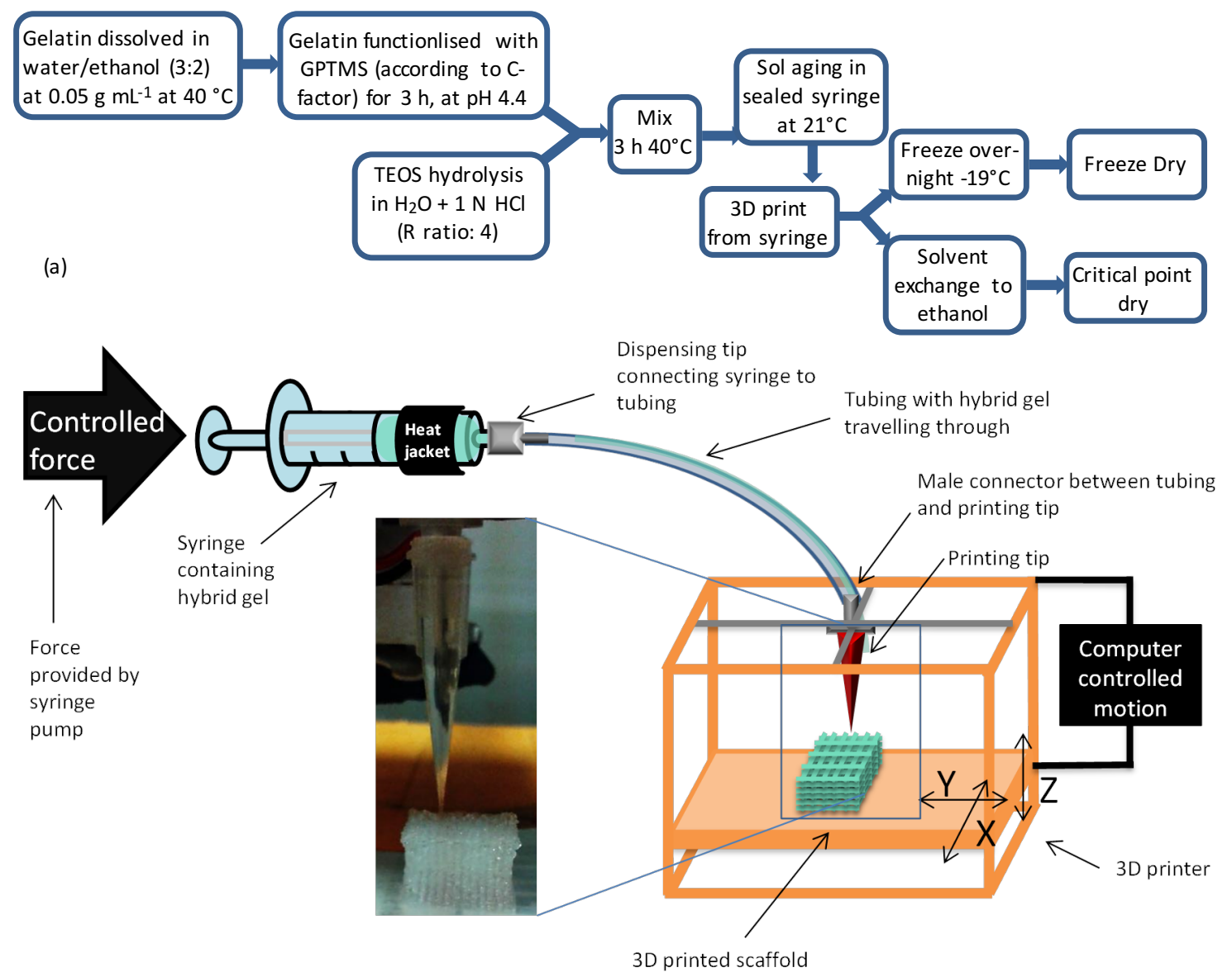


Figure 1. Schematics of (a) the sol-gel hybrid synthesis method; (b) the 3D printing set-up including an image of scaffold being 3D printed (inset).

On exiting the nozzle, the gels were required to hold their shape and scaffolds were built layer-by-layer without collapse. This required the gel to be in a specific gel strength range, termed "printing window". The hybrid inks were classified into 3 stages: i) not gelled enough for printing, "sol-aging"; ii) printable, the "printing window"; iii) too gelled for printing, "overgelled". The timeframe for each stage of hybrid gelation was investigated, the solutions were monitored and 3D printing was attempted regularly (1 $\mathrm{h}$ intervals).

Rheometry of the ink was critical for printing. The storage and loss modulus of $78 \mathrm{G}$ CF 500 hybrid inks were measured at: 7, 9, 11, 13, $15 \mathrm{~h}$ after mixing. A Discovery Hybrid Rheometer, TA instruments (New Castle, US), was used in oscillatory mode. First, the Linear Viscoelastic Region (LVR) of the material was determined by an oscillation-amplitude test (0.1-100\% strain rate) performed under the conditions: $1 \mathrm{~mm}$ gap, $40 \mathrm{~mm}$ stainless steel plate, $40^{\circ} \mathrm{C}, 30 \mathrm{~s}$ soak time, $10 \mathrm{rad} \mathrm{s}^{-1}$ frequency using a solvent trap. A $10 \%$ strain was found to be within the LVR so oscillation-frequency tests $(0.1-100 \mathrm{~Hz})$ were performed under the conditions: $1 \mathrm{~mm}$ gap, $40 \mathrm{~mm}$ stainless steel plate, $40^{\circ} \mathrm{C}, 30 \mathrm{~s}$ soak time, $10 \%$ strain.

\subsection{Characterisation of 3D printed scaffold}

Skeletal (strut) density $\left(\rho_{s}\right)$ values were obtained by helium pycnometry (Quantachrome Ultrapycnometer, measured 20 times in triplicate). Percentage porosity $(\varphi)$ was calculated according to Eq. , where $\rho_{\mathrm{t}}$ is the total/bulk scaffold density (measured geometrically) and $\rho_{\mathrm{s}}$ is the skeletal density:

$$
\begin{array}{ll}
\text { Porosity, } \varphi=\left(1-\frac{\rho_{t}}{\rho_{s}}\right) \times 100 & \text { Eq. } 3:
\end{array}
$$

Samples were coated in $5 \mathrm{~nm}$ chromium (Quorum, Q150T) and secondary electron images were obtained using a JEOL JSM 6010 SEM in normal scanning mode with an accelerating voltage of $20 \mathrm{kV}$, working distance of $19 \mathrm{~cm}$, spot size of 50 . Channel width and strut width were measured using ImageJ software (30 struts and 30 channels per sample, three samples).

X-ray microtomography $(\mu \mathrm{CT}) 3 \mathrm{D}$ reconstructions of the scaffolds were generated from tomographs at the Diamond Manchester Imaging Beamline I13 under the conditions of $0.1^{\circ}$ intervals, $1 \mathrm{~s}$ exposure, $12 \mathrm{keV}$ beam energy. The tomographs obtained were then layered 
and rendered using Avizo software to generate the 3D reconstructions of the scaffolds and the internal pores.

Dissolution in Tris(hydroxymethyl) aminomethane (Tris) buffer solution was investigated. Tris buffer was prepared by dissolving $6.118 \mathrm{~g}$ of Tris in $1000 \mathrm{~mL}$ of distilled water. The $\mathrm{pH}$ was adjusted to 7.4 by addition of $1.0 \mathrm{M} \mathrm{HCl}$ at $36.5^{\circ} \mathrm{C} .150 \mathrm{mg}$ of dried scaffold was immersed in $100 \mathrm{~mL}$ of Tris solution $(\mathrm{n}=3)$, as recommended ${ }^{32}$. At each of the 12 time points, $1 \mathrm{~mL}$ solution was removed for inductively coupled plasma optical emission spectroscopy analysis (ICP, Thermo Scientific iCAP 6300 , flow rate of $1.5 \mathrm{~mL} \mathrm{~min}^{-1}$ and plasma power of $1300 \mathrm{~W}$ with auto sampler (ASX-520) $(n=3))$ and $25 \mu \mathrm{L}$ aliquots for gelatin detection by BCA assay (standard procedure using Pierce Micro BCA protein assay $(n=3)$, with gelatin solution standard and $4 \mathrm{~h}$ incubation). The removed solution was replenished with fresh Tris solution.

Compression testing was carried out using a TA ElectroForce ${ }^{\circledR} 3200$ Series III, on 1:1 cube scaffolds ( $n=8$ ), using a $440 \mathrm{~N}$ load cell and compression rate of $0.5 \mathrm{~mm} \mathrm{~min}^{-1}$.

\subsection{Cell culture}

All cell culture reagents were obtained from Invitrogen and Sigma-Aldrich (UK) unless specified otherwise. ATDC5 cell line (ATCC, UK) was culture expanded in basal DMEM supplemented with $5 \%$ (v/v) FCS (foetal calf serum), $1 \%(\mathrm{v} / \mathrm{v})$ penicillin/streptomycin and 1 $\times$ ITS liquid supplement. Pre-osteoblast cell line MCT3T3 cells were culture expanded in basal $\alpha$-MEM supplemented with $10 \%(\mathrm{v} / \mathrm{v})$ FCS and $1 \%(\mathrm{v} / \mathrm{v})$ penicillin/streptomycin. Upon confluence, cells were passaged using $500 \mu \mathrm{g} \mathrm{mL}^{-1}$ trypsin-EDTA (ethylene diamine tetraacetic acid).

\subsubsection{Cell viability}

The in vitro cytotoxicity of the material was examined by assessing the metabolic activity of ATDC5 and MCT3T3 cells after exposure to the dissolution products of the 78G CF 500 material, in accordance to ISO 10993-5 and ISO 10993-12. Dissolution products released by the powder form of the $78 \mathrm{G} \mathrm{CF} 500\left(0.2 \mathrm{~g} \mathrm{~mL}^{-1}\right.$ in DMEM and $\alpha-M E M$ at $\left.37^{\circ} \mathrm{C}\right)$ over a $72 \mathrm{~h}$ period were prepared. Medical grade polyethylene (PE) was used as non-cytotoxic negative control and polyurethane (PU) containing $0.1 \%(\mathrm{w} / \mathrm{w})$ zinc diethyldithiocarbamate (ZDEC) was used as positive control, which induces reproducible cytotoxic response. The dissolution products were filter sterilised and dilution series (25\%, $50 \%, 75 \%$ and $100 \%)$ were prepared and mixed with basal supplements prior to use in cell viability assays.

Cell viability was assessed by a calorimetric based on the conversion of 3-(4,5dimethylthiazol-2-yl)-2,5-diphenyltetrazolium bromide (MTT) into formazan. The cells were 
seeded at $1 \times 10^{4}$ cells per well on 96-well plates and left to grow in respective basal media for $24 \mathrm{~h}$. The media was replaced with fresh basal media, dissolution products of 78G CF 500 scaffolds or controls and cultured for a further $24 \mathrm{~h}$. The culture media was removed and MTT diluted in serum-free media $\left(1 \mathrm{mg} \mathrm{mL}^{-1}\right)$ was added. Following an incubation period of 2 $\mathrm{h}$, the MTT solution was replaced with $100 \mu \mathrm{L}$ DMSO and shaken briefly to dissolve the formazan derivatives. The optical density was measured spectrophotometrically at $570 \mathrm{~nm}$ using a microplate reader (SpectraMax M5).

\subsubsection{Cell attachment}

A cell attachment study was performed using ATDC5 and MCT3T3 cell lines on the 78G CF $5003 \mathrm{D}$ printed scaffolds (approximately $5 \times 5 \times 2 \mathrm{~mm}^{3}$ ). The scaffolds were sterilised with 70 $\%$ ethanol, washed with copious amount of PBS and placed into sterile $50 \mathrm{~mL}$ centrifuge tubes fitted with filter caps. $5 \mathrm{~mL}$ of cell suspension containing $3 \times 10^{6}$ cells in basal media was added to each centrifuge tube containing the scaffolds and incubated for $2 \mathrm{~h}$, with gentle agitation every 30 minutes to allow for diffusion and well-distributed cell adhesion. Cell-seeded scaffolds were collected on day 3 and analysed for cell attachment by immunohistochemistry staining for cytoskeletal protein.

\subsubsection{Cartilaginous matrix formation}

A 28 day cartilaginous matrix formation study using ATDC5 cells was performed on scaffolds with two channel widths: $200 \mu \mathrm{m}$ (CPD) and $700 \mu \mathrm{m}$ (FD). The number of cells were adjusted as per the difference in volume of the scaffolds: $3 \times 10^{6}$ cells (for $200 \mu \mathrm{m}$ channel width) or $10 \times 10^{6}$ (for $700 \mu \mathrm{m}$ channel width) cells were seeded as described above. On day 3 , basal DMEM was replaced by chondrogenic media and cultured for further 28 days with media change every 3-4 days. The chondrogenic media was made up of DMEM supplemented with $10 \mathrm{ng} \mathrm{mL}^{-1}$ rhTGF-ß3 (100-36E, PeproTech, UK), $100 \mu \mathrm{M}(28.95 \mu \mathrm{g} \mathrm{mL}$

$\left.{ }^{1}\right)$ L- Ascorbic acid 2-phosphate, $10 \mathrm{nM}\left(3.92 \mathrm{ng} \mathrm{mL}^{-1}\right)$ dexamethasone and $1 \times$ ITS liquid supplement, a modification of the media described in previous studies ${ }^{33,34}$. After 28 days, the seeded scaffolds were analysed for chondrogenic differentiation and cartilaginous matrix formation.

\subsubsection{Immunohistochemistry}

Cell-seeded constructs were fixed with 4\% paraformaldehyde (PFA) at day 3 or 28 and used for immunohistochemical analysis of cell attachment and cartilaginous matrix formation. Following permeabilisation with buffered $0.5 \%$ (v/v) Triton X-100 in PBS (300 mM sucrose, $50 \mathrm{mM} \mathrm{NaCl}, 3 \mathrm{mM} \mathrm{MgCl}_{2}, 20 \mathrm{mM}$ HEPES and $\mathrm{pH}$ 7.2) and blocking with $10 \mathrm{mg} \mathrm{mL}^{-1} \mathrm{BSA}$ in PBS, samples were incubated with relevant primary antiserum at $4{ }^{\circ} \mathrm{C}$ overnight. This was 
followed by hour-long incubation with Alexa Fluor ${ }^{\circledR} 488$-conjugated secondary antibody. Cytoskeletal marker anti-Vimentin antibody (rabbit polyclonal, IgG, Abcam, Cambridge, UK) was used at a dilution of 1:500 dilution in $10 \mathrm{mg} \mathrm{mL}^{-1} \mathrm{BSA}$ in PBS. Chondrogenic differentiation and cartilaginous matrix markers, anti- Sox9, Aggrecan, Collagen Type II, Collagen Type I and Collagen Type $X$ antibodies were used at dilutions of 1:150, 1:500, 1:500, 1:1000 and 1:100 respectively. F-actin was labelled using CytoPainter F-actin staining kit (Abcam, Cambridge, UK) following the manufacture's instruction. Briefly, Alexa Fluor ${ }^{\circledR}$ 568-conjugated phalloidin (1:1000 dilution in labelling buffer) was added simultaneously with the secondary antibody during the incubation period. All samples were counter-stained with DAPI (0.1 $\mu \mathrm{g} \mathrm{mL}^{-1}$ in PBS) and imaged under confocal microscopy (Leica SP5 MP laser scanning confocal microscope and software, Leica Microsystems, Wetzlar, Germany).

\subsubsection{Gene expression analysis}

Day 28 constructs were lysed and total RNA was extracted using Qiagen RNeasy kit (Qiagen, UK) following maunfacturer's instructions. The RNA samples were treated with DNase-1 reagent and reverse-transcribed using the SuperScript ${ }^{\circledR}$ VILO $^{\mathrm{TM}}$ kit (Invitrogen, UK). qPCR assays were carried out using the QuantStudio ${ }^{\mathrm{TM}} 6$ Flex system (Thermo Fisher, UK) for analysing the expression genes including: Sox9 (F: 5'-ctgaagggctacgactggac-3'; R: 5'-gaggaggaatgtggggagtc-3'), Aggrecan (F: 5'-aggaggtggtactgctggtg-3'; R: 5'tctcactccagggaactcgt-3'), Col2a1 (F: 5'-agtcaagggagatcgtggtg-3'; R: 5'-cgtcgtgctgtctcaaggta3'), Col1a1 (F: 5'-gagaagtctcaagatggtggc-3'; R: 5'-gcggggtcggagccctcgctt-3'), Col10a1 (F: 5'gccaagcagtcatgcctgat-3'; R: 5'-gacacgggcatacctgttacc-3'). The expression of genes of interest was normalised to the endogenous control GAPDH (F: 5'-gggtggagccaaacgggtc-3'; R: 5'-ggagttgctgttgaagtcgca-3'). The relative transcript levels of genes of interest were analysed using the comparative $C_{T}$ method $\left(\Delta \Delta C_{T}\right.$ method). Statistical analysis was performed at the level of $\Delta \mathrm{C}_{\mathrm{T}}$.

\subsubsection{GAG quantification}

The quantity of sulphated GAGs synthesized by cells following 28-day culture on 78G CF 500 scaffolds was determined using the DMMB assay ${ }^{35}$. Day-28 samples were digested overnight at $60{ }^{\circ} \mathrm{C}$ with papain (working solution of $0.7 \mathrm{U}$ papain prepared in papain buffer containing $8.2 \mathrm{mg} \mathrm{mL}^{-1}$ sodium acetate, $37 \mathrm{mg} \mathrm{mL}^{-1}$ disodium EDTA and $0.79 \mathrm{mg} \mathrm{mL}^{-1}$ cysteine hydrochloride in potassium phosphate buffer consisting of $27.2 \mathrm{mg} \mathrm{mL}^{-1}$ monobasic potassium phosphate and $34.8 \mathrm{mg} \mathrm{mL}^{-1}$ dibasic potassium phosphate, $\mathrm{pH} 6.4$ ). $20 \mu \mathrm{L}$ of the diluted extract (1:10 dilution in papain buffer) was then mixed with $200 \mu \mathrm{L}$ DMMB reagent (16 $\mu \mathrm{g} \mathrm{mL} \mathrm{m}^{-1} \mathrm{DMMB}, 2 \mathrm{mg} \mathrm{mL}^{-1}$ sodium formate, $0.5 \%(\mathrm{v} / \mathrm{v})$ ethanol and $0.2 \%(\mathrm{v} / \mathrm{v})$ formic acid) and optical density of the resultant solution was measured at $540 \mathrm{~nm}$. The GAG 
content for each sample was normalised to the weight of blank scaffold measured on day 0 . Results were expressed as mean \pm SD.

\section{Results}

\subsection{Hybrid ink composition and structural evolution}

Efficacy of the covalent coupling by GPTMS between the silica and gelatin networks was investigated using the ninhydrin reaction to test for free amino acids and by applying Equation 1. Importantly, covalent coupling was successful using GPTMS. The degree of crosslinking increased linearly as C-factor increased from CF 0 to CF 500 (Figure 2a), however the increase in crosslinking, relative to amount of GPTMS added, was reduced as C-factor increased above CF 500. To avoid excess GPTMS in the hybrid system, a CF 500 was used for the silica-gelatin hybrid inks to determine the printing window.

Definition of the "printing window" is that within the printing window, the hybrid ink has sufficient viscosity that enabled the ink to retain its shape after extrusion from the syringe and onto the substrate, but the viscosity is not so high that the ink cannot be extruded from the syringe. The ink was able to be laid down layer-by-layer and resulting scaffolds were stable 3D printed structures. As gelatin content in the ink increased, the sol aging time and printing window widened (Figure 2b). A composition of 78G CF 500 was most efficient for use with the printing method as it required $8 \mathrm{~h}$ of sol aging (additional time it was left in a sealed container after the $3 \mathrm{~h}$ mixing of the silica sol and functionalised gelatin prior to printing), after which the ink was able to be $3 \mathrm{D}$ printed for $4 \mathrm{~h}$. The storage and loss modulus measured between $7 \mathrm{~h}$ and $15 \mathrm{~h}$ of sol aging indicated an increasingly crosslinked gel which displayed no shear thinning behaviour (Figure S1). Direct writing or Robocasting techniques usually rely on the ink having shear thinning behaviour ${ }^{36}$. Instead, the ability to print came from the gel strength rather than viscoelastic behaviour. Rather than flowing through the tubing and nozzle, the highly crosslinked hybrid gel was forced under controlled pressure along the tubing and was able to hold its shape on exiting the nozzle. 

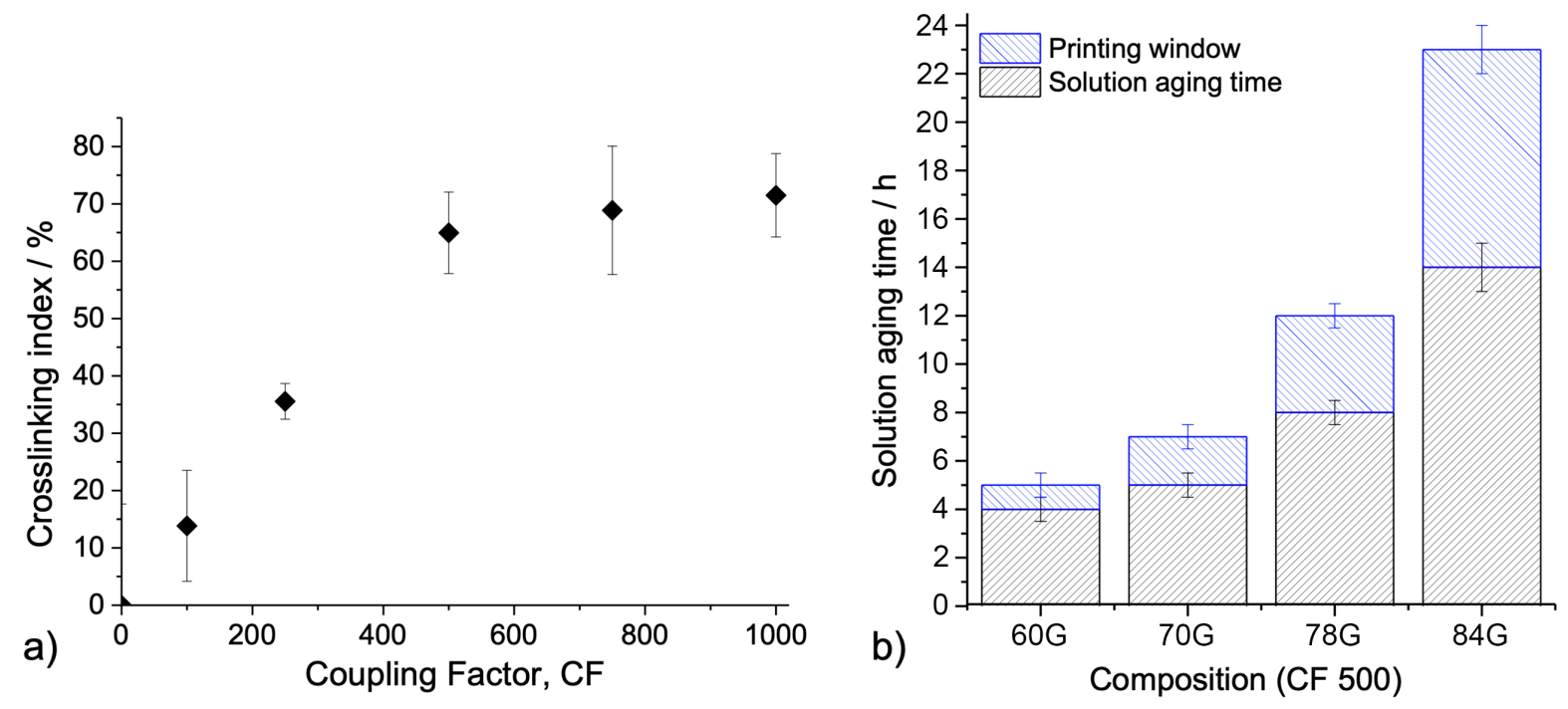

Figure 2. Determining the most suitable silica-gelatin hybrid composition for 3D printing inks: a) crosslinking index as a function of CF (molar ratio of GPTMS to gelatin); b) solution aging time and printing window of hybrid inks (CF 500) with respect to gelatin content.

A functionalisation time for gelatin with GPTMS of $3 \mathrm{~h}$ was selected as it reduced the rate of gelation, when mixed with the silica sol, maximising the time that the ink was within the printing window. The aging temperature was reduced from $40^{\circ} \mathrm{C}$ to $21^{\circ} \mathrm{C}$ to prevent collapse of the scaffolds due to flow of gelatin. The adapted method for printing was therefore: $3 \mathrm{~h}$ functionalization (CF 500) and 1 week aging at $21^{\circ} \mathrm{C}$.

The effect of a reduced functionalisation time and aging temperature on the evolution of the hybrid structure for $78 \mathrm{G}$ CF 500 hybrids were assessed by solid state ${ }^{29} \mathrm{Si}$ MAS NMR (Figure 3). The 78G CF500 hybrids were produced using four different methods, one of which was the previously developed sol-gel foaming that used hydrofluoric acid (HF) to accelerate gelation of the silicate ${ }^{20}$. Method A was the newly developed method for the 3D printing ink: $3 \mathrm{~h}$ functionalisation with room temperature aging; Method B used a $14 \mathrm{~h}$ functionalisation, as did Methods $\mathrm{C}$ and $\mathrm{D}$; in Method $\mathrm{C}$ gelation was accelerated with the addition of HF; and Method $\mathrm{D}$ was the sol-gel foaming method, gelled with $\mathrm{HF}$, with an elevated aging temperature of $40^{\circ} \mathrm{C}$. Table 1 shows quantification of the relative proportions of the $T^{n}$ species, $Q^{n}$ species and degree of connectivity $\left(D_{c}\right)$. 


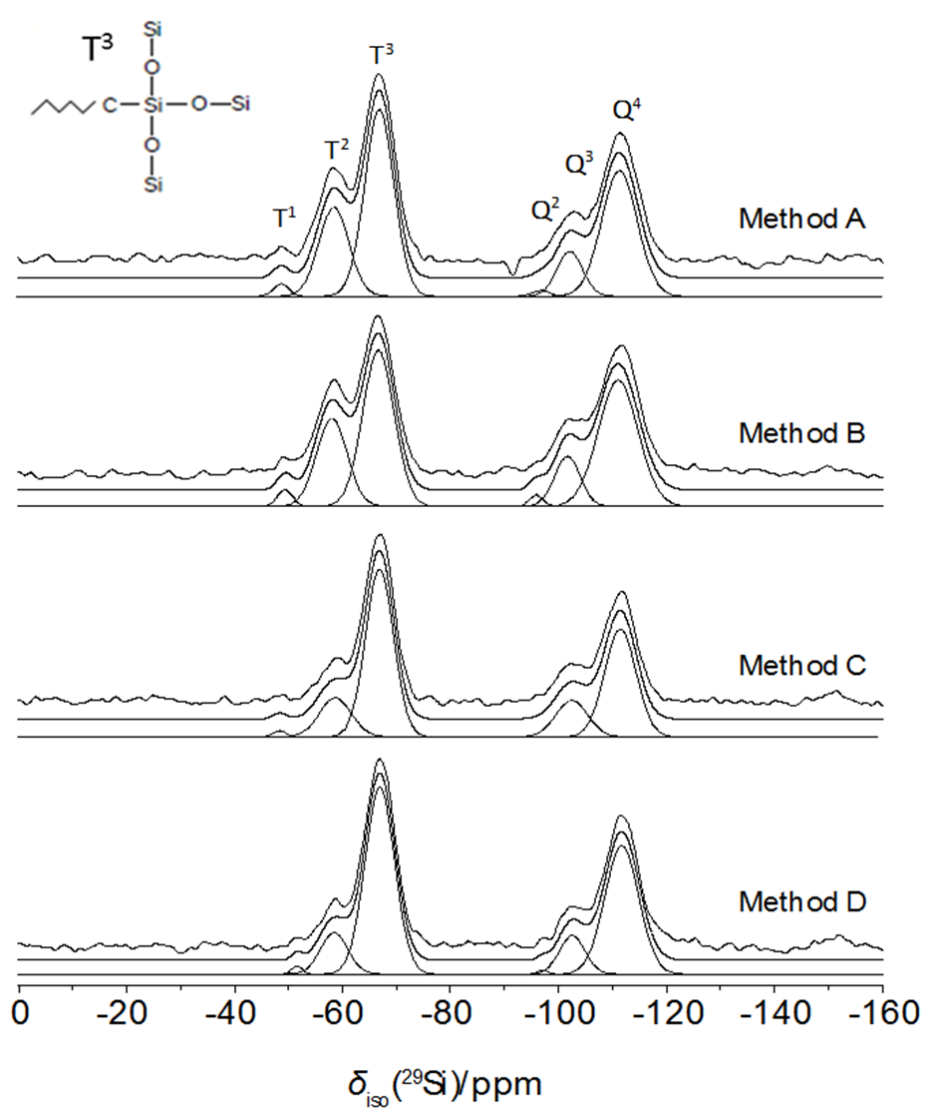

Figure 3. ${ }^{29}$ Si solid state single pulse MAS NMR spectra for Methods A, B, C, and D with a schematic of the $\mathrm{T}^{3}$ structure (inset). Method $A=3 \mathrm{~h}$ GPTMS functionalisation, printed;

Method B = 14 h GPTMS functionalisation, printed; Method C : 14 h GPTMS + HF, printed; $14 \mathrm{~h}$ GPTMS functionalisation + direct foaming (no printing) + HF, aged at $40^{\circ} \mathrm{C}$.

The longer functionalisation time resulted in a similar $D_{c}(\sim 90 \%)$ as $\mathrm{T}^{3}$ decreased from $39 \%$ to $34 \%$ and $\mathrm{Q}^{4}$ increased from $32 \%$ (Method $A$ ) to $35 \%$ (Method B). Adding HF catalysis (Method $C$ ) caused a $\sim 4 \%$ increase in $D_{c}$, the most significant increase in $D_{c}$ of all the parameters investigated. HF affected the $\mathrm{T}$ structure, as the relative proportion of $\mathrm{T}^{1}$ more than halved for Method C; $\mathrm{T}^{2}$ decreased from $19 \%$ to $12 \%$; and $\mathrm{T}^{3}$ increased from $34 \%$ to $45 \%$. As aging temperature increased (Method D), $Q^{4}$ increased from $32 \%$ to $36 \%$, as the higher temperature allowed gelatin chain movement and further condensation of the silicate, but $D_{c}$ was similar. Aging at $40^{\circ} \mathrm{C}$ also caused $3 \mathrm{D}$ printed scaffolds to collapse, due to flow of the gelatin. As use of HF would complicate the process, and longer functionalisation time was not beneficial, Method A was taken forward for printing.

The results agreed with FTIR spectra (Figure S2), which showed $3 \mathrm{~h}$ functionalisation time to reduce Si-O-Si bonding prior to TEOS addition into the hybrid system, as band ratios for Si$\mathrm{O}-\mathrm{Si}$ compared to the Si-C band were 2.2 and 2.5 when for $3 \mathrm{~h}$ and $14 \mathrm{~h}$ respectively. 
Table 1. T structure, $Q$ structure, and degree of condensation quantified by ${ }^{29} \mathrm{Si}$ MAS NMR for hybrids synthesised using four different methods: A, B, C, and D. The composition of all hybrid are 78G CF 500. Insert shows the chemical structure of a silicon $T^{3}$ species (silicon in GPTMS with 3 bridging oxygens).

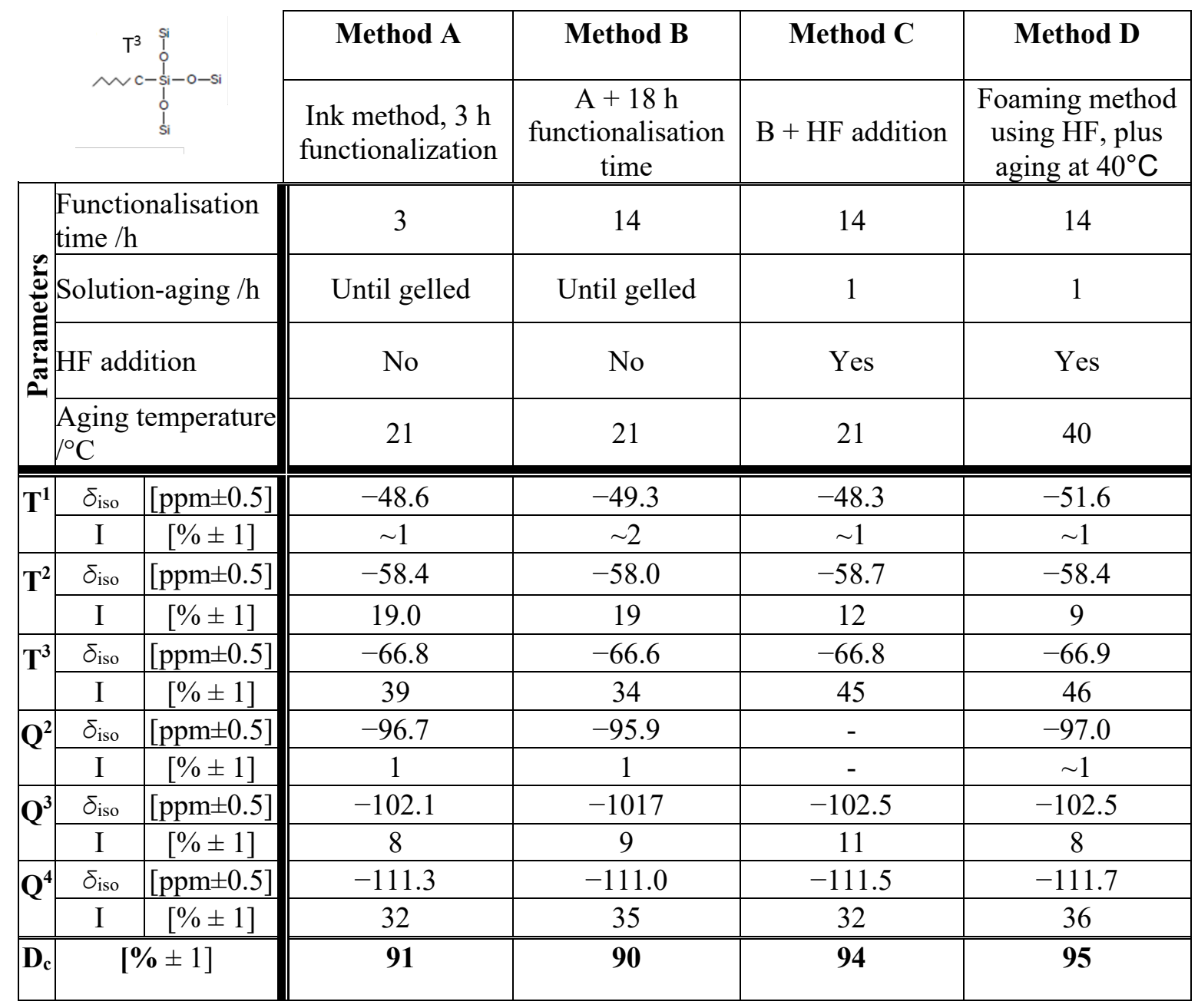

\subsection{D printed scaffold architecture evolution}

Two methods for drying the 3D printed hybrids were compared: freeze-drying (FD), which was the initial method used to sol-gel hybrid foams ${ }^{20}$; and critical point drying. FD avoids the transition from liquid to gas when removing aqueous solvent from a frozen material, as water is removed from the scaffold by sublimation of ice, which reduces the large shrinkage that would occur in ambient drying, but capillary stresses are experienced.

CPD is a drying technique which eliminates capillary stresses by avoiding the effects of liquid surface tension ${ }^{37}$, but for the silica/gelation system, a solvent exchange was required, to pure ethanol. The ethanol is in turn replaced with liquid $\mathrm{CO}_{2}$. When the temperature $\left(31.1^{\circ} \mathrm{C}\right)$ and pressure $(1170 \mathrm{psi})$ are elevated above the critical point, the $\mathrm{CO}_{2}$ liquid and 
vapour states are indistinguishable and in this super-critical state have the same density and surface tension. The liquid is then heated to convert the liquid to the gas phase without any distortion of the morphology. Gelatin alone is typically not compatible with this process, due to precipitation in ethanol, however in a hybrid system with covalent coupling, shrinkage rather than precipitation was predicted.

As a result, freeze drying (FD) and critical point drying (CPD) produced scaffolds with different overall size, strut width and channel size, even though the same printing fidelity of a $200 \mu \mathrm{m}$ nozzle (nominal strut width) and $1 \mathrm{~mm}$ strut separation (nominal channel width) were used. SEM images ( $\mathrm{x}, \mathrm{y}$ plane) and $\mu \mathrm{CT}$ reconstructions presented in Figure 4 show that all scaffolds comprised of open channels and vertical walls in the vertical $z$ (build) direction clearly seen in the FD scaffolds (Figure 4a, b, e, f). Horizontal channels were clear in the FD scaffolds (Figure 4c), similar to the $z$ orientation, but were smaller and lower in number in the CPD scaffolds (Figure 4g). Negative 3D representations made by filling the pores and removing the scaffold, in the 3D image processing (Figure 4d and Figures 4h,i), showed high connectivity of pores in the FD scaffolds but more oriented pore channels in the $z$ direction for the CPD scaffolds.

a)

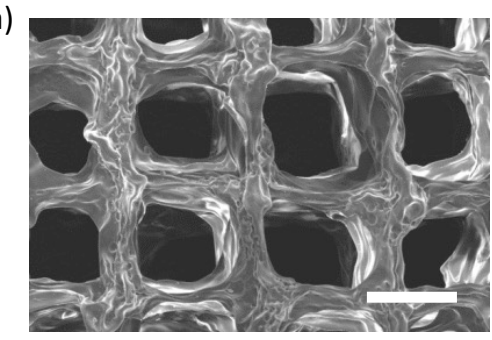

Freeze-dried

$$
\text { CPD }
$$

e)

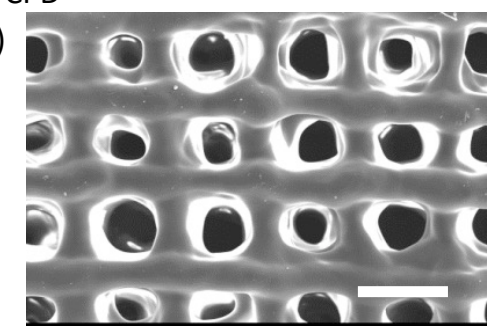

b)

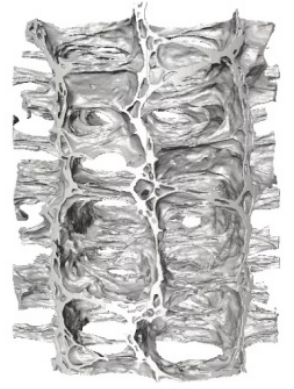

f)

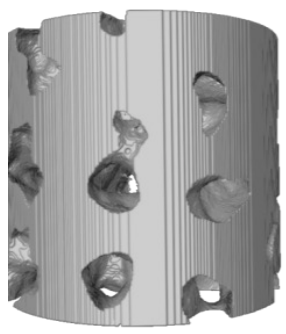

c)

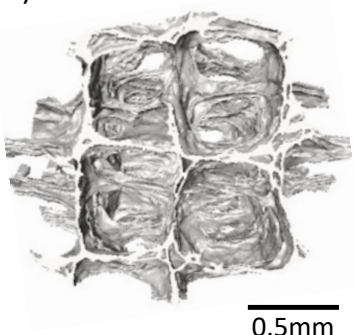

g)

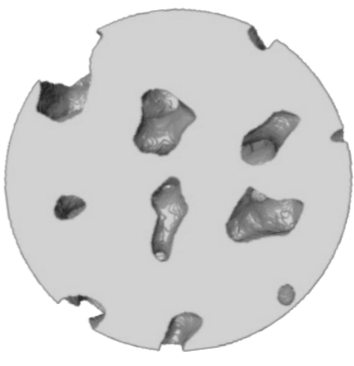

d)
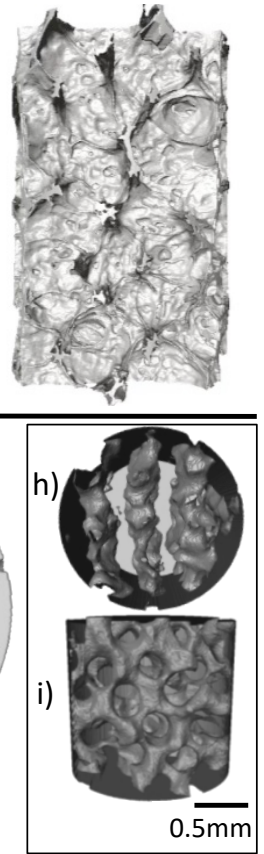

Figure 4. Imaging of 3D printed hybrid scaffolds using two drying methods: a-d) Freeze-dried, FD and e-i) critical point dried, CPD: (a,e) SEM images in the $z$ direction of the $x, y$ plane, scale bar is $500 \mu \mathrm{m}$; (b, c, d, f, g) $\mu \mathrm{CT}$ 3D reconstructions of scaffolds; (h,i) $\mu \mathrm{CT}$ 3D reconstructions of porosity (negative image). $\mu \mathrm{CT}$ images of scaffolds are viewed in the $y, z(b, f), x, y(c, g, h)$ and $x, z$ (d,i) plane ( $\mu \mathrm{CT}$ images from Diamond Light Source). 
In these 3D grid-like scaffolds, the term "channel size" is equivalent to the interconnected pore size in foam-like scaffolds. The channel size and strut sizes are summarised in Table 2. FD resulted in $682 \pm 92 \mu \mathrm{m}$ channels ("FD700") with $<40 \mu \mathrm{m}$ struts whereas CPD resulted in $210 \pm 53 \mu \mathrm{m}$ channels ("CPD200") with $162 \pm 27 \mu \mathrm{m}$ struts. The porosity was calculated to be $88 \%$ and $72 \%$ for FD and CPD scaffolds respectively, using volume measurements and skeletal density values of $1.5 \mathrm{~g} \mathrm{~cm}^{-3}$ and $1.7 \mathrm{~g} \mathrm{~cm}^{-3}$ respectively in Equation 3 . The porosity results seem to agree with Figure 4(h,i). The reduced pore channel size and increased strut thickness in the CPD was due to the increased shrinkage. Importantly, shrinkage was approximately isotropic, minimising distortion. The swelling of the scaffolds after $24 \mathrm{~h}$ in TRIS was therefore higher for CPD scaffolds than FD scaffolds, $156 \pm 7 \%$ versus $112 \pm 3 \%$ respectively.

Table 2. The mean channel width for FD and CPD scaffolds with $1 \mathbf{~ m m}$ printed strut separation. Errors represent the standard deviation ( 30 struts and channels were measured over three samples).

\begin{tabular}{|c|c|c|c|c|c|}
\hline $\begin{array}{c}\text { Drying } \\
\text { method }\end{array}$ & $\begin{array}{c}\text { Shrinkage during } \\
\text { drying/ \% }\end{array}$ & $\begin{array}{c}\text { Mean } \\
\text { channel } \\
\text { width/ } \boldsymbol{\mu m}\end{array}$ & $\begin{array}{c}\text { Mean strut } \\
\text { width/ } \boldsymbol{\mu m}\end{array}$ & $\begin{array}{c}\boldsymbol{\varphi} \text {, Porosity/ } \\
\mathbf{\%}\end{array}$ & Scaffold ID \\
\hline FD & $42 \pm 0$ & $682 \pm 92$ & $<40$ & $88 \pm 1$ & FD700 \\
\hline CPD & $80 \pm 1$ & $210 \pm 53$ & $162 \pm 27$ & $72 \pm 0$ & CPD200 \\
\hline
\end{tabular}

\subsection{Dissolution study}

In the dissolution study silicon release from the FD and CPD samples had a similar profile for the first $72 \mathrm{~h}$ (Figure 5) but total silicon release was less for CPD scaffolds (105 $\mu \mathrm{m} \mathrm{mL}^{-1}$ ) than for FD scaffolds $\left(117 \mu \mathrm{m} \mathrm{mL}^{-1}\right)$. The gelatin release, $\sim 32 \mu \mathrm{m} \mathrm{mL}^{-1}$, was consistent independent of drying method. 


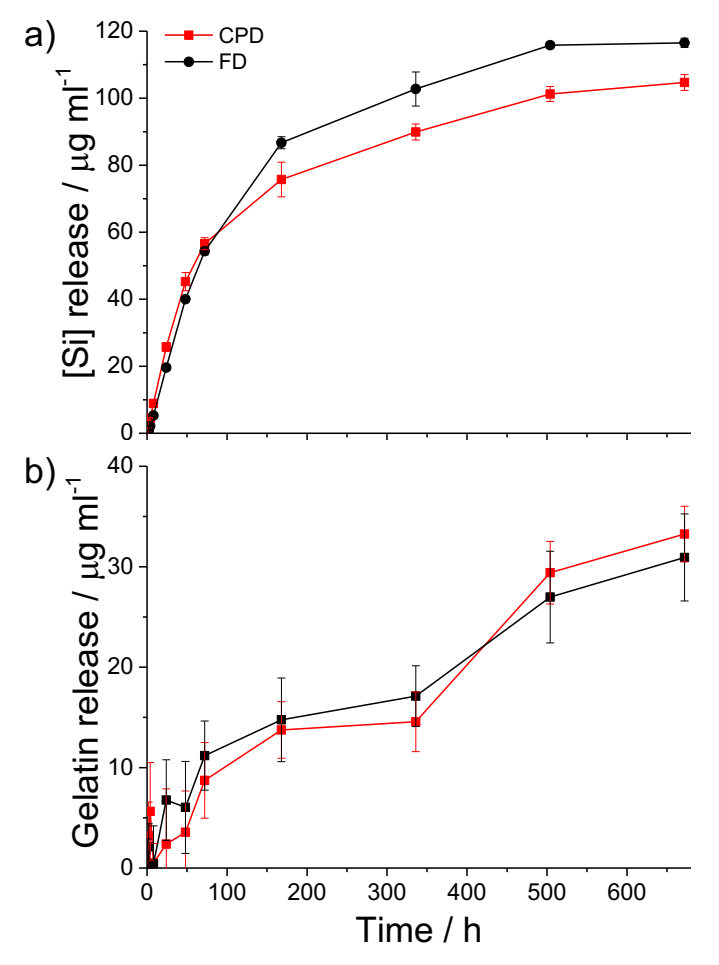

Figure 5. Dissolution profile in TRIS buffer for 3D printed hybrid scaffolds dried by freeze drying (FD700) and critical point drying (CPD200): concentration of a) silicon; b) gelatin.

The silicon and gelatin release was calculated as a percentage of the initial inorganic (hydrolysed TEOS and GPTMS silanol groups) and organic (gelatin and GPTMS organic chains) mass. The initial organic: inorganic ratio for CPD and FD scaffolds were 72:28 and 70:30 respectively as determined by TGA (Figure S3). For dissolution, $150 \mathrm{mg}$ of scaffold was used, hence for FD scaffolds, $45 \mathrm{mg}$ was the inorganic and $105 \mathrm{mg}$ was organic. Therefore $26 \%$ of the total inorganic was released as silicon species and $3 \%$ of the total organic content of the scaffold was released as gelatin. For CPD scaffolds dissolution was similar with $25 \%$ of the inorganic released and $3 \%$ of the organic released. After the one month study, the scaffolds had not changed in appearance as the low gelatin release resulted in volume stability of the scaffolds.

\subsection{Compression testing}

Representative plots of the stress strain curve for each type of scaffold tested are shown in Figure 6 and Table 3 gives the mean values obtained from compression testing and compares to hyaline cartilage. It is important how scaffolds behave when immersed in body fluid, so mechanical properties were assessed after 1 week immersion in TRIS buffer. The compressive strength and Young's modulus of the FD700 reduced by $\sim 90 \%$, from $1 \mathrm{MPa}$ to $0.1 \mathrm{MPa}$, as result of the week immersion in TRIS, and compressive strain doubled, from 0.1 to 0.2 , which is likely to be due to the dissolution of silica and swelling, which increased the 
water content and reduced the scaffold density. The compressive strength of the wet CPD200 scaffolds was over 10 times greater (1.3 MPa) than that of the wet FD700 scaffolds $(0.1 \mathrm{MPa})$ due to the increased strut/wall width and reduced percentage porosity, even though dissolution was similar (Figure 5). The Young's modulus of the wet FD700 scaffolds was $0.7 \pm 0.1 \mathrm{MPa}$, which is within the range of hyaline cartilage (0.5-1.0 MPa). As seen in Figure 6, the FD scaffolds had an approximately linear stress-strain relationship before yield, whereas CPD scaffolds showed a non-linear response.

Table 3. Mechanical properties hyaline cartilage and dry and wet (1 week immersion in TRIS) 3D printed scaffolds, made with $78 \mathrm{G}$ CF 500, dried via FD and CPD $(n=>6)$.

\begin{tabular}{|c||c|c|c|}
\hline Sample & $\begin{array}{c}\text { Compressive } \\
\text { strength /MPa }\end{array}$ & $\begin{array}{c}\text { Young's } \\
\text { modulus, E /MPa }\end{array}$ & Compressive Strain \\
\hline FD dry & $1.0 \pm 0.1$ & $7.1 \pm 0.9$ & $0.1 \pm 0.02$ \\
\hline FD wet & $0.1 \pm 0.02$ & $0.7 \pm 0.1$ & $0.2 \pm 0.03$ \\
\hline CPD wet & $1.3 \pm 0.04$ & $\mathrm{n} / \mathrm{a}$ & $0.5 \pm 0.04$ \\
\hline $\begin{array}{c}\text { Hyaline } \\
\text { cartilage }\end{array}$ & $22-37^{38,39}$ & $0.5-1.0^{40-42}$ & $0.24-0.85^{40,43}$ \\
\hline
\end{tabular}

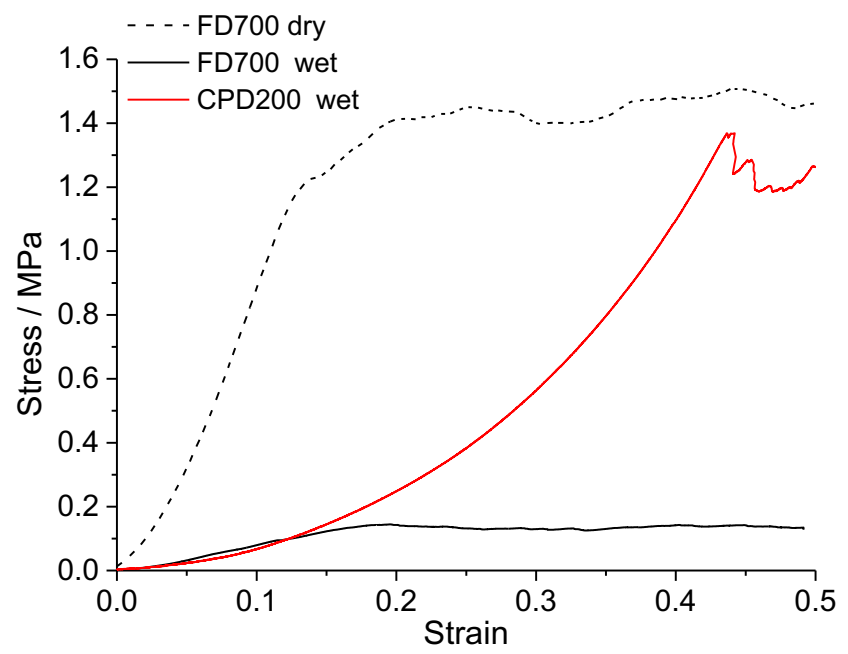

Figure 6. Example stress-strain plots of 3D printed hybrid scaffolds under compression: wet and dry FD700 scaffolds and wet CPD200 scaffolds. Solid lines indicate wet samples (1 week immersion in TRIS), dashed line indicates dry samples. 


\subsection{Cell studies}

\subsubsection{Biocompatibility and cell attachment}

Results of MTT assays of ATDC5 chondrogenic cells and MCT3T3 pre-osteoblast cells, after exposure to the dissolution products of the $78 \mathrm{G}$ CF 500 scaffolds (Figure 7a), indicated the scaffolds can pass the ISO standards in vitro cytotoxicity of medical devices for biological device evaluation. An absorbance value less than $70 \%$ of that of the control/standard culture conditions would suggest cytotoxicity. Toxicity was only observed for the PU controls. The well organised actin and well-defined vimentin markers in Figure $7 \mathrm{~b}$ indicate robust attachment of ATDC5 cells, which spread across the surface. МСT3T3 cells also attached to the scaffolds, as shown in Figure 7c.
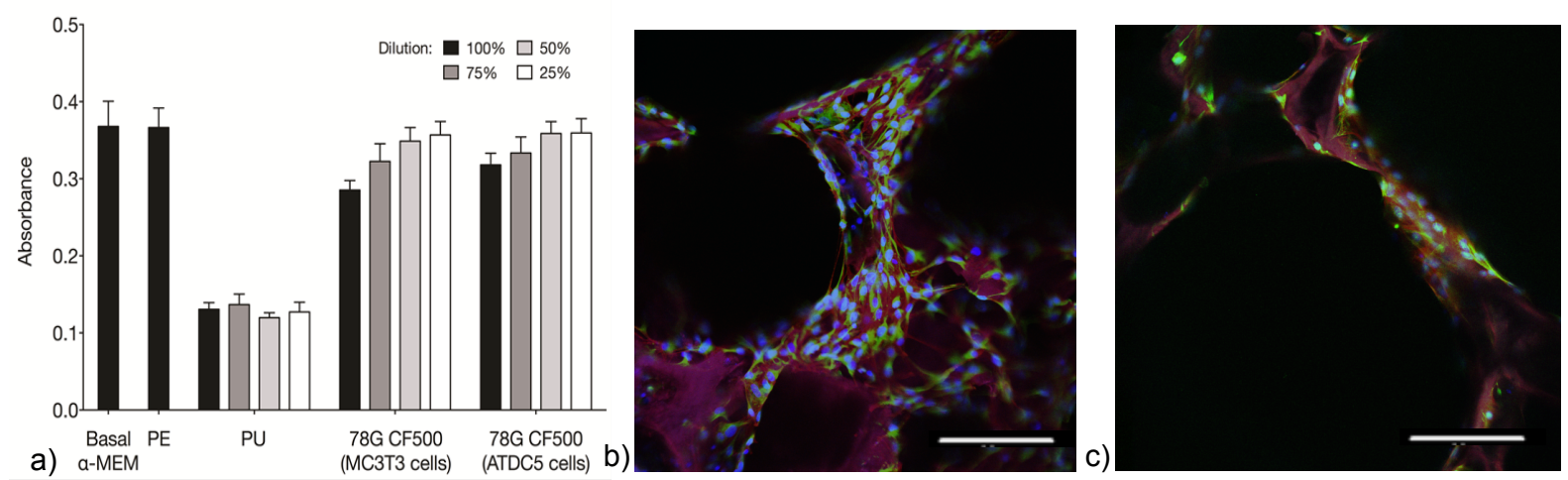

Figure 7. a) MTT metabolic activity assay according to the ISO standards 10993-5 and 10993-12. Dilution \% values are vol\% concentrations in basal media for ATDC5 chondrogenic cells and MCT3T3 osteoblast cells after $24 \mathrm{~h}$ culture $(n=3)$. Confocal images of cells on the 3D printed scaffolds stained for cytoskeletal protein actin (red), vimentin (green) and nuclei (blue): (b) ATDC5 and (c) MCT3T3. Scale bars are $200 \mu \mathrm{m}$.

\section{Cartilage matrix formation}

The difference in channel size, brought about by the post printing drying method, affected ATDC5 cell behaviour (Figure 8). Cells cultured on the CPD200 demonstrated robust chondrogenic differentiation and hyaline-like cartilaginous matrix formation (Figure 8). Sox9, a marker for chondrogenic differentiation, was localised in the majority of cells. The dense extracellular matrix, which could occupy the entire pore structure, was composed of collagen Type II, a key marker for hyaline articular cartilage and cartilage specific aggrecan, the major non-collagenous component. Collagen Type II and aggrecan were sparse in the FD700 scaffold with larger pores. However, the expression of collagen Type I, a marker for fibrocartilage (among other tissues), was present in FD700 and not present in CPD200. Similar outcomes were shown for ATDC5 culture in other 3D printed hybrid scaffolds, in that case comparing $\sim 200 \mu \mathrm{m}$ channels with $500 \mu \mathrm{m}$ channels of 
silica/poly(tetrahydrofuran)/polyTHF/poly( $\varepsilon$-caprolactone) hybrids ${ }^{28}$. Here, to determine whether increasing the seeding cell number, for the freeze-dried scaffolds with $700 \mu \mathrm{m}$ pore channels, would improve cell-cell interactions, the number of cells seeded was increased to $10 \times 10^{6}$. Collagen Type II and aggrecan were highly expressed at the increased cell density, but the presence of collagen Type I in FD700 scaffolds persisted.
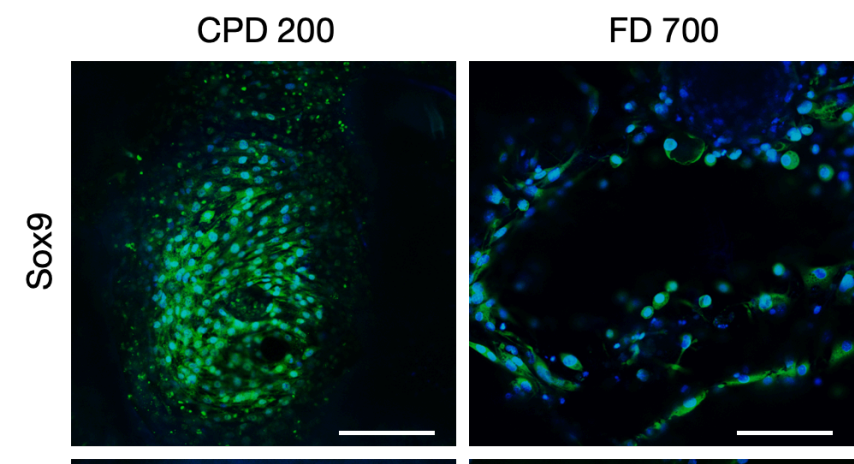

FD $700 \mathrm{w} / 3 \mathrm{x}$ cell no.
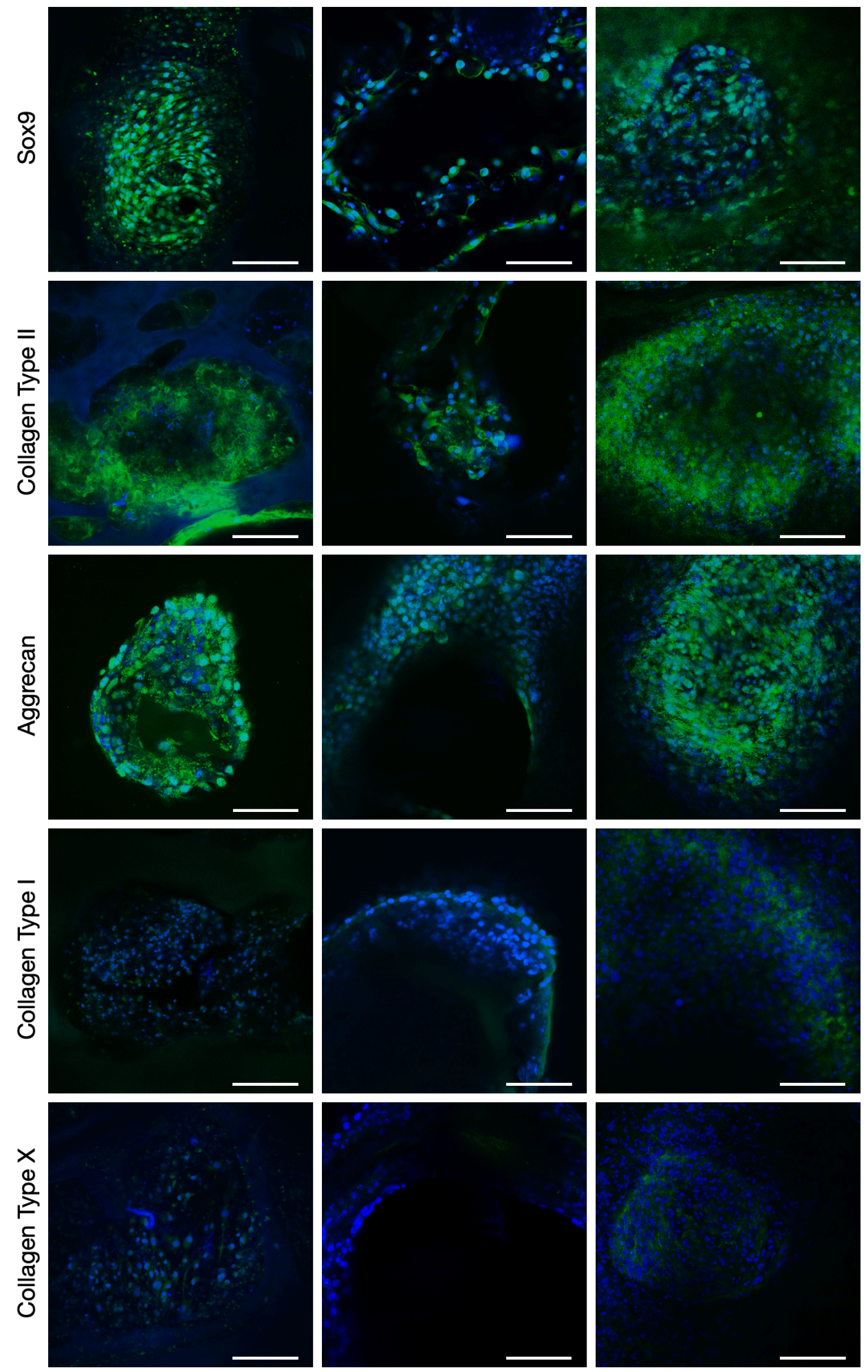
Figure 8. Confocal images of ATDC5 cells cultured in the 3D printed scaffolds that were: critical point dried with a $200 \mu \mathrm{m}$ pore channel size (CPD200); freeze dried (FD) with a $700 \mu \mathrm{m}$ pore channel size (FD700) and the FD700 scaffolds with a 3x higher seeding cell number. Staining was for cytoskeletal proteins at 28 days of culture: Sox9, collagen type II, aggrecan, collagen type I, collagen type $X$ (all green) and nuclei (blue). Scale bars are $200 \mu \mathrm{m}$.

The gene expression analysed by quantitative PCR in Figure 9 confirmed the observations from immunohistochemical staining. Sox9, COL2a1 and Aggrecan were all expressed significantly more by ATDC5 cells cultured in the scaffolds with $200 \mu \mathrm{m}$ channels than in scaffolds with $700 \mu \mathrm{m}$ channels, when the same number cells were used. When the cell number was tripled in the FD700 scaffolds, the expression of Sox9 on CPD200 and FD700 (with high seeding cell numbers) scaffolds were similar, but the levels of cartilage matrix specific gene Col2a1 and Aggrecan were still significantly higher for cells cultured on CPD200 scaffolds. The expression of Col1a1 by ATDC5 cells on FD700 scaffolds was significantly higher in comparison to those on CPD200 scaffolds, even with the similar cell density. The level of Col10a1 was similar in all three conditions, however, it should be noted that the $\mathrm{C}_{\mathrm{T}}$ values were in the range of 29 to 31 , indicating the expression of Col10a1 gene can be regarded as negligible.
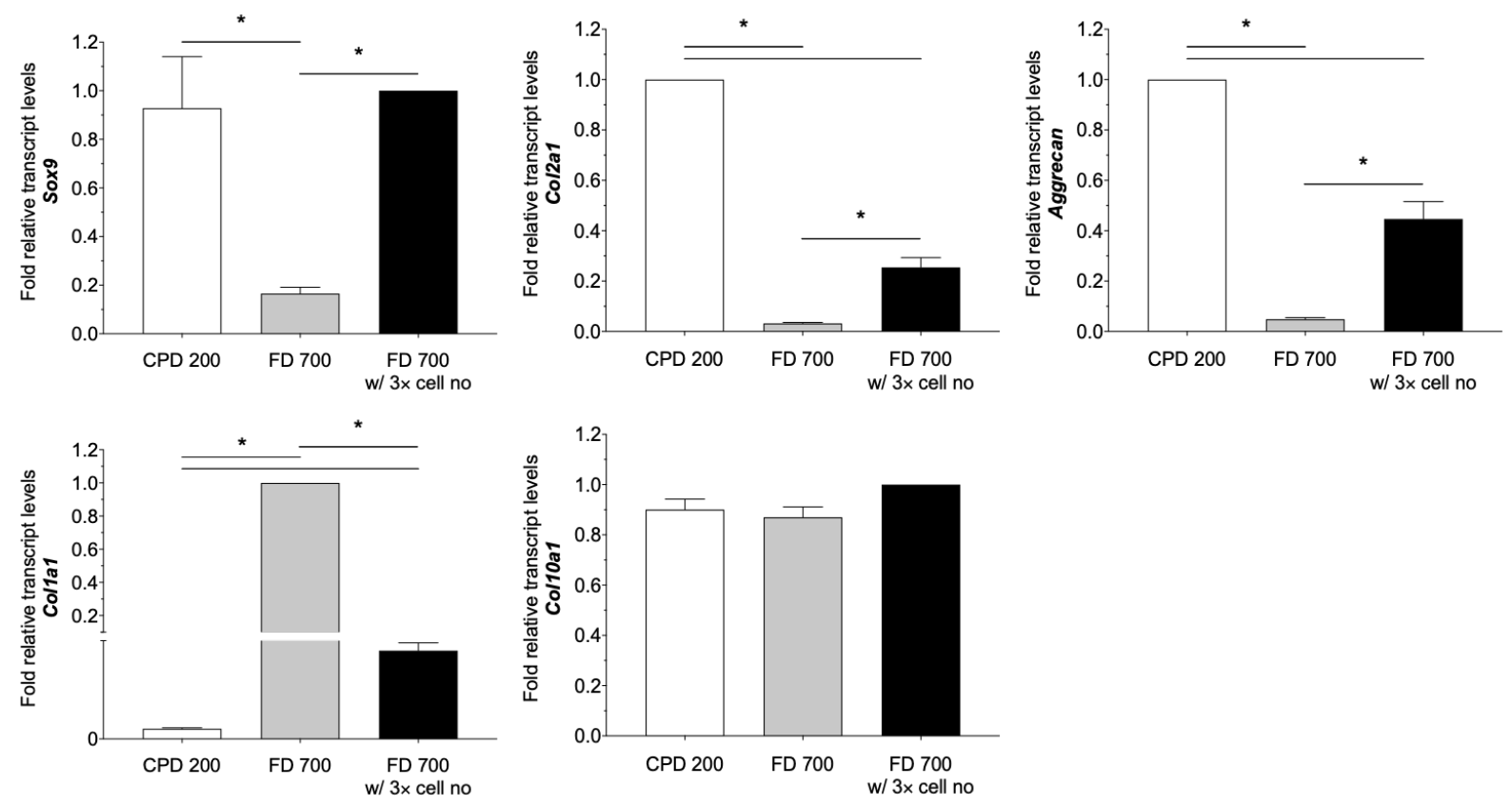

Figure 9. qPCR analysis of gene expression (Sox9, Col2a1, Aggrecan, Col1aI, Col10a1) from ATDC5 cells cultured for 28 days on the 3D printed scaffolds including: critical point dried (CPD) with a $200 \mu \mathrm{m}$ pore channel size (CPD200); freeze dried (FD) with a $700 \mu \mathrm{m}$ pore channel size (FD700) and the FD700 scaffolds seeded with a $3 \times$ higher cell number. The results were normalised to the transcript level of GAPDH housekeeping gene. Fold relative transcript 
level of target gene was calculated using comparative $\Delta \mathbf{C}_{T}$ method (i.e. $2^{-\Delta \Delta C T}$ ) and the group with the highest relative transcript level was assigned to a value of 1 . Statistical analysis was performed at the level of $\Delta C_{T} . n=3$ and * indicates $p<0.05$.

The formation of glycosaminoglycan, the main non-collagenous component of cartilage matrix, was also appears more efficient on CPD200 scaffolds compared to FD700 as shown in Figure 10. Only by increasing the cell seeding number did the GAG levels of the cells within the FD700 scaffold reach those cultured in the $200 \mu \mathrm{m}$ pore channels.

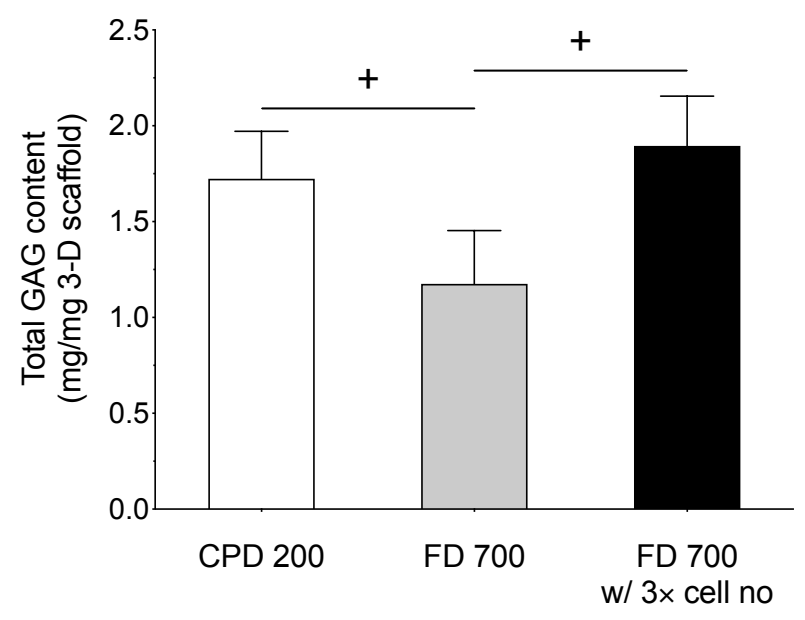

Figure 10. Quantitative glycosaminoglycan (sGAG) assay after 28 days of ATDC5 cells culture in scaffolds FD700, CF200 and FD700 with 3x the cell number. $n=3$ and + indicates $0.05<p<$ 0.1.

\section{Discussion}

The hybrid ink composition chosen was 78G CF 500. A CF of 500 was selected as increasing the CF above this value did not further improve the crosslinking in the hybrid. This was not due to saturation of functionalisation sites on the gelatin molecules as CF 500 corresponds to a molar ratio of GPTMS to amino acids involved in functionalisation (glutamic and aspartic acid) of $0.27^{44,45}$. It is likely the kinetics of the reaction slowed, due to reduced availability of binding sites and oligomer formation above this ratio of GPTMS to gelatin. The ink composition found most suitable for 3D printing via this Direct Ink Writing extrusion method was $78 \mathrm{G}$ CF 500, due to the convenient gelation rate and large printing window. The rate of silica network condensation was reduced as gelatin content increased and increasing the GPTMS could not compensate for the reduction in TEOS content and gel strength.

A combination of the ninhydrin assay and solid state NMR results showed that covalent coupling between the gelatin and silica network was successful, using GTPMS, and reducing 
the functionalisation time for gelatin with GPTMS form $14 \mathrm{~h}$ to $3 \mathrm{~h}$ had little effect on $\mathrm{D}_{\mathrm{c}}$ and the $D_{c}$ was similar to that of the sol-gel foaming method ${ }^{20}$.

The structure and properties of 3D printed scaffolds dried via CPD were found to be preferable for cartilage tissue regeneration. CPD scaffolds produced channels with widths of $210 \mu \mathrm{m}$, which was similar to channel sizes for other hybrid scaffolds shown to support hyaline articular-cartilage-like matrix formation in vitro ${ }^{28,29}$, which agrees with earlier hypotheses on the ideal 3D environment for cartilage cells ${ }^{46}$. The FD scaffolds had pore channels that were over three times larger: $682 \mu \mathrm{m}$. Using CPD, the scaffolds retained rounded struts with a mean width of $162 \mu \mathrm{m}$, whereas during FD struts shrank to $<40 \mu \mathrm{m}$ and appeared to be fragmented (Figure 4), perhaps due to ice crystals forming in the struts during freezing, which were then removed in the freeze drying, without allowing consolidation of the struts by continued gelation. In fact, the struts were similar to the thin pore walls that resulted from the sol-gel foaming process, which also employed freeze-drying 20.

The low degree of swelling (156 \% for CPD and 114\% for FD scaffolds) showed considerable improvement on the hybrids 3D printed by Gao et al. (440 \% swelling in just 2 h). The low swelling was due to the high degree of covalent coupling, which prevented water from entering the gelatin network ${ }^{47}$. The success of the covalent coupling was confirmed by solid state NMR and the ninhydrin assay. However, the coupling may have been less than achieved previously in the sol-gel foaming process ${ }^{20}$. Here, despite a similar degree of silica network condensation $\left(D_{c}\right), T^{1}$ and $T^{2}$ increased at the expense of $T^{3}$ in the 3D printed scaffolds, compared to the foams. This reduced coupling may benefit low stiffness applications, such as cartilage regeneration.

Under compressive loading, the scaffolds dried using CPD had a compressive strength (1.3 $\pm 0.04 \mathrm{MPa}$ ) approximately ten times that of FD scaffolds $(0.1 \pm 0.02 \mathrm{MPa})$, due to the increased strut/wall width and reduced total porosity. The strain-strain response of the CPD scaffolds was non-linear displaying increased stiffness with increased loading, a viscoelastic response similar to native hyaline cartilage ${ }^{43} 48$, whereas the FD scaffold exhibited a linear stress-strain response. The change in behaviour is predicted to arise from the higher degree of swelling of the CPD scaffolds and larger strut width which allowed densification of the material during compression by expulsion of water molecules from the gelatin network. As shown in Figure 7, organisation of actin and vimentin are well defined in ATDC5 cells in comparison to MC3T3 cells. This could be due to the scaffold having a lower stiffness than bone matrix ${ }^{41}$, again confirming the $78 G$ CF 500 is a more suitable substrate for cartilage regeneration applications. 
The pore channel size affected the type of matrix produced in the scaffolds during cell culture in vitro. After 28 days of culture in the CPD200 scaffolds, ATDC5 chondrocytes demonstrated robust chondrogenic differentiation and hyaline-like cartilaginous matrix formation in CPD200 scaffolds compared to those cultured in FD700 scaffolds. Immunohistochemistry (Figure 8) and gene expression analyses (Figure 9) confirmed significantly increased expression of both protein and gene expression of relevant markers in CPD200 scaffolds, including Sox9, Collagen Type II and Aggrecan. There was noticeable expression of Collagen Type I in FD700 scaffolds, an indication of undesirable fibrous tissue formation, this was not present in CPD200 scaffolds. Formation of sulphated GAG was also parse in FD700 scaffolds. Collagen Type $X$ was negligible in all culture conditions. These results indicate that hyaline-like cartilage matrix was produced when cells were cultured in a structure with $200 \mu \mathrm{m}$ pore channels, but when the pore channel size increased, the cells produced fibrocartilage-like matrix. This could be due to the type of cell-cell interactions within the pore channels.

The pore architecture, such as porosity, pore size and interconnectivity, of a scaffold are influential in controlling cell distribution, mass transportation via diffusion and chondrogenic differentiation ${ }^{49}$. The 3D printed 78G CF 500 scaffolds contained approximately $72 \%$ (CPD) and $88 \%$ (FD) porosity, which may have contributed to the sufficient mass exchange during the prolonged culture period. Similar results were seen previously in silica/poly(tetrahydrofuran)/polyTHF/poly( $\varepsilon$-caprolactone) hybrids ${ }^{28,29}$. The hypothesis was that pore channels that have widths of $\sim 200-250 \mu \mathrm{m}$ allow chondrocytes to have 3D cell-cell interactions, whereas in the larger pores (e.g. $>500 \mu \mathrm{m})$ the cells flatten against the scaffold struts/ pore walls and dedifferentiate into fibroblasts ${ }^{29}$. Here, in the larger pores, the cells may be in too low a density for 3D interactions. They may flatten to the surface of the struts, as was seen for MSCs on other hybrid scaffolds ${ }^{29}$. This was tested by increasing the cell number. While the difference between the scaffold types was less, there the fibrocartilage matrix markers (collagen Type I) still dominated.

The exact effects of pore size on the formation of cartilaginous matrix remain inconclusive and further studies are needed to investigate this hypothesis, however, previous work has shown in scaffolds containing smaller pores, chondrocytes reach higher cell density and cellcell interactions were improved, resulting in enhanced cell proliferation, GAG and collagen content ${ }^{50,51}$. Pore size could affect cell spreading due to the amount of available surface area for cells. It has been demonstrated for fibroblasts that the extent of cell spreading plays an important role in activation of signal transduction mechanism and the subsequent cellular behaviour ${ }^{52}$ and when chondrocytes attach and spread in a $2 \mathrm{D}$ environment, they can 
undergo dedifferentiation, resulting in Collagen Type I production ${ }^{53-55}$. Indeed, notably increased amount of Collagen Type I was observed in cells cultured in FD 700 scaffolds with larger pores $(700 \mu \mathrm{m})$. It is likely that, cells cultured in the larger pores experienced environments closer to 2D culture, spreading along the struts/ pore walls, resulting in increased chondrocyte dedifferentiation.

Higher cell density may also have caused decreased apoptosis, another mechanism that likely contributed to increased cartilaginous tissue formation. It has been shown that aggregated chondrocytes (similar to those resides in small pores) demonstrated a significant decrease in the number of cells undergoing apoptosis ${ }^{56}$. Increasing the seeding cell number in the FD700 scaffolds appeared to improve chondrogenic differentiation to a level comparable to CPD200 scaffolds, as evidenced by Sox9 gene expression. The formation of cartilaginous matrix however remain suboptimal with the persistent existence of Collagen Type I. It should also be noted that in clinical settings, it is not always feasible to achieve high cell number especially in patients whose cartilage is already severely damaged and/or those with other underlying diseases.

\section{Conclusion}

Silica-gelatin sol-gel Class II hybrids were developed as new biomaterial inks for 3D printing for use in combination with microfracture surgery to encourage functional hyaline articular cartilage regeneration. The 78G CF 500 hybrids were compatible with an optimised 3D printing protocol, which avoided rapid gelation, but retain high levels of coupling and sol-gel network condensation. Critical point drying and freeze drying were compared as drying techniques after printing. The 3D printed scaffolds showed a low degree of swelling in buffer solutions. Critical point drying produced scaffolds with mechanical properties close to native cartilage and pore channels of $\sim 200 \mu \mathrm{m}$ proved capable of supporting hyaline-like cartilaginous matrix formation, in terms of collagen type II, Sox9 and Aggrecan production in vitro, with little collagen type I or X expression.

\section{ACKNOWLEDGEMENTS}

The authors acknowledge support from the EPSRC (EP/I020861/1). P.D.L. acknowledges support from a Royal Academy of Engineering Chair in Emerging Technology. J.V.H. also thanks the EPSRC and the University of Warwick for partial funding of the solid-state NMR infrastructure at Warwick, and acknowledges additional support for this infrastructure obtained through Birmingham Science City: Innovative Uses for Advanced Materials in the Modern World (West Midlands Centre for Advanced Materials Projects 1 and 2), with support from Advantage West Midlands (AWM) and partial funding by the European Regional 
Development Fund (ERDF). M.M.S. was funded by the grant from the UK Regenerative Medicine Platform "Acellular / Smart Materials - 3D Architecture" (MR/R015651/1). Raw data is available on request from rdm-enquiries@imperial.ac.uk.

\section{Supplementary information}

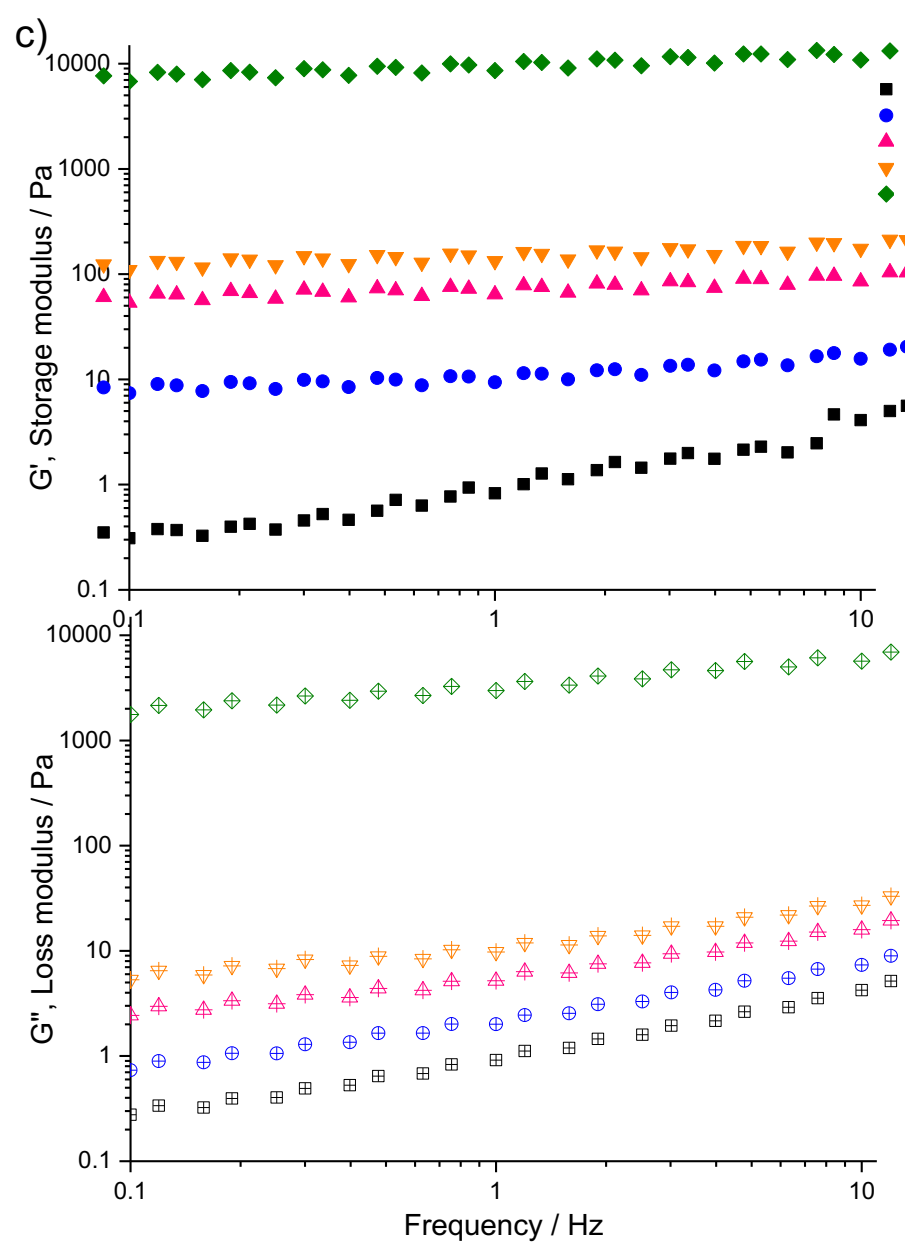

Figure S1. Storage and loss moduli of 78G CF 500 hybrid gels measured using oscillationfrequency tests between $7 \mathrm{~h}$ and $15 \mathrm{~h}$ after mixing the hybrid components. The rheology of the 78G CF 500 hybrids was monitored during the solution aging period, within the 3D printing window, and after the solution had become too gelled for printing. The plots of the storage and loss modulus indicate a highly crosslinked gel with no shear thinning behaviour. 


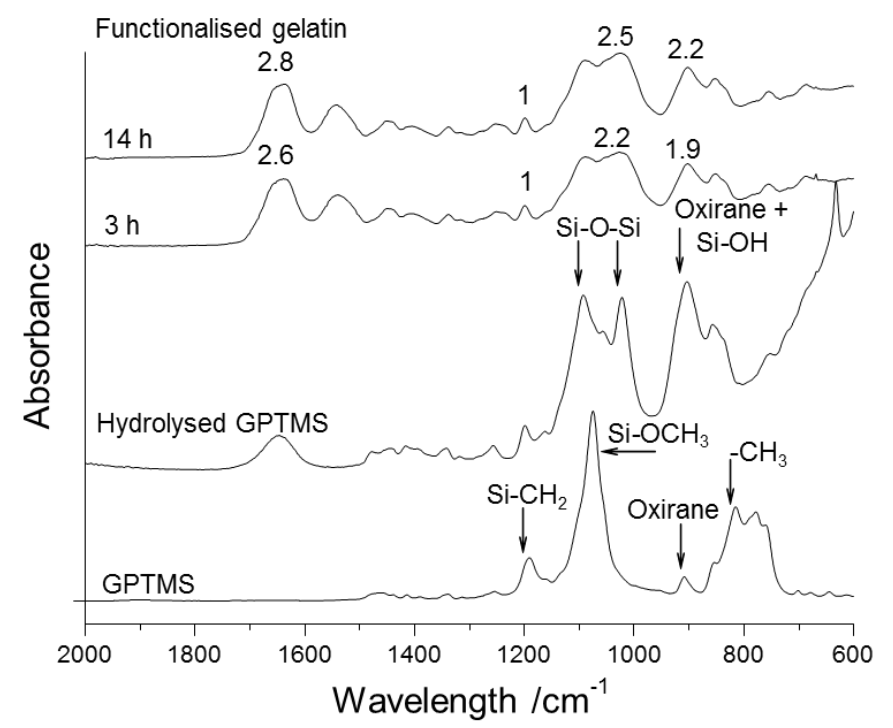

Figure S2. FTIR spectra of GPTMS before and after hydrolysis and gelatin functionalised by GPTMS for $3 \mathrm{~h}$ and $14 \mathrm{~h}$. Band ratios are displayed relative to the Si-C band.

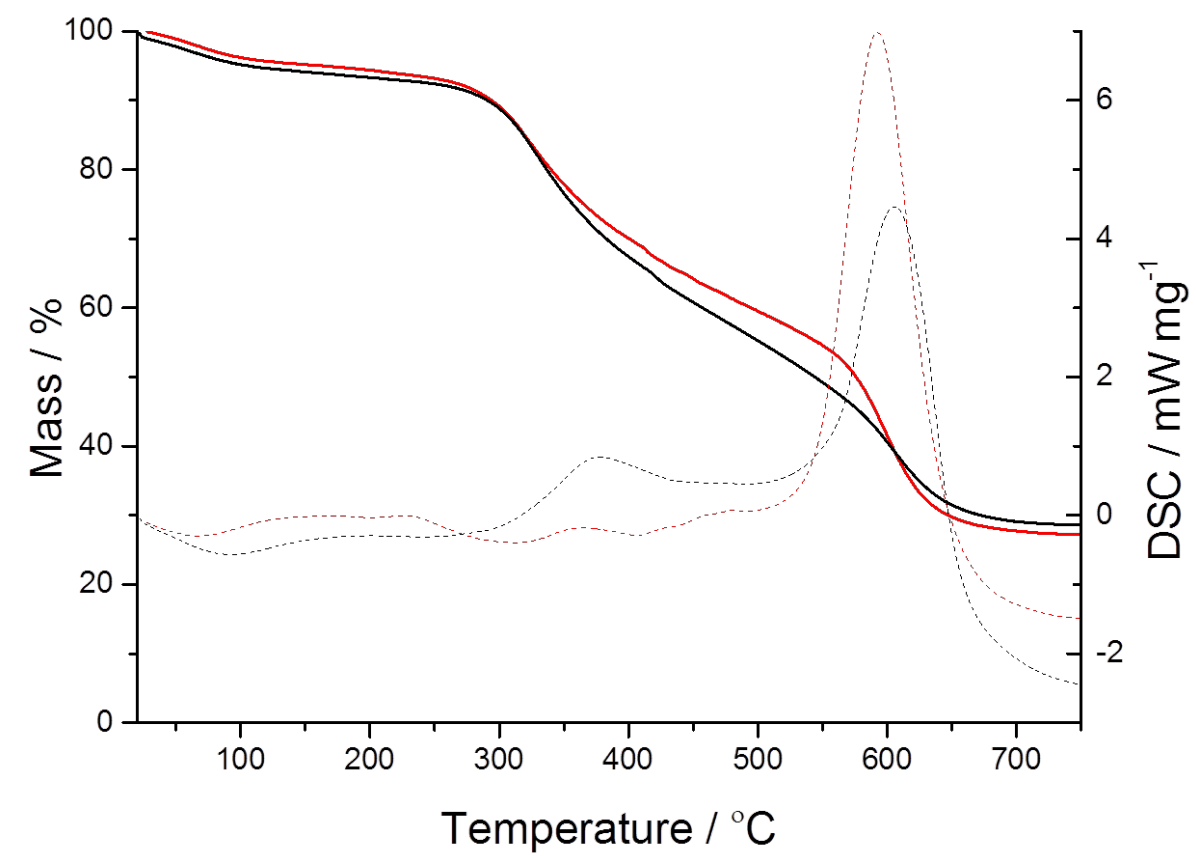

Figure S3. TGA and DSC analysis comparing hybrid 78G CF500 scaffolds dried via FD and CPD. 


\section{References}

1. Mithoefer, K., et al., Am. J. Sports Med. (2009) 37 (10), 2053

2. Goldring, M. B., Therapeutic Advances in Musculoskeletal Disease (2012) 4 (4), 269

3. $\quad$ Oliveria, S. A., et al., Arthritis and Rheumatism (1995) 38 (8), 1134

4. $\quad$ Steadman, Jr., and Sterett, W. I., Med. Sci. Sports Exerc. (1995) 27 (3), 328

5. $\quad$ Giannini, S., et al., Injury (2010) 41 (11), 1196

6. Benthien, J. P., and Behrens, P., Knee Surg Sports Traumatol Arthrosc (2011) 19 (8), 1316

7. $\quad$ Gille, J., et al., Knee Surg Sports Traumatol Arthrosc (2010) 18 (11), 1456

8. $\quad$ Schagemann, J., et al., Arch Orthop Trauma Surg (2018) 138 (6), 819

9. Baba, R., et al., Am J Sports Med (2018) 46 (8), 1970

10. Almeida, H. V., et al., Tissue Eng Part A (2017) 23 (1-2), 55

11. Koh, Y. G., et al., J. Tissue Eng. (2019) 10

12. Kwan, H., et al., Materials (2020) 13 (2)

13. Setayeshmehr, M., et al., Tissue Eng. Part B (2019) 25 (3), 202

14. Camarero-Espinosa, S., et al., Biomater. Sci. (2016) 4 (5), 734

15. Vunjak-Novakovic, G., et al., Biotechnology Progress (1998) 14 (2), 193

16. Sobral, J. M., et al., Acta Biomater (2011) 7 (3), 1009

17. Dong, C. J., and Lv, Y. G., Polymers (2016) 8 (2)

18. Ito, A., et al., Journal of Bioscience and Bioengineering (2003) 95 (2), 196

19. Kirchmajer, D. M., and Panhuis, M. I. H., J. Mat. Chem. B (2014) 2 (29), 4694

20. Mahony, O., et al., Adv. Funct. Mater. (2010) 20 (22), 3835

21. Mahony, O., et al., J. Sol-Gel Sci. Technol. (2014) 69 (2), 288

22. Jones, J. R., Acta Biomater (2013) 9 (1), 4457

23. Poologasundarampillai, G., et al., Soft Matter (2012) 8 (17), 4822

24. Keri, M., et al., Acta Biomater (2020) 105, 131

25. Veres, P., et al., J. Non-Cryst. Solids (2017) 473, 17

26. Greenhalgh, R. D., et al., J. Mater. Sci. (2017) 52 (15), 9066

27. Gao, C., et al., J. Biomed. Mater. Res. Part A (2013) 101 (7), 2027

28. Tallia, F., et al., Mater Horiz (2018) 5, 849

29. Li, S., et al., Biomater. Sci. (2020)

30. Lai, J. Y., et al., PLoS One (2013) 8 (1)

31. Poologasundarampillai, G., et al., J. Mater. Chem. (2010) 20 (40), 8952

32. Maçon, A. L. B., et al., Journal of Materials Science: Materials in Medicine (2015) 26 (2), 115

33. Mackay, A. M., et al., Tissue Eng. (1998) 4 (4), 415

34. Li, S., et al., J Biomater Appl (2015) 29 (6), 824

35. Knight, M. M., et al., Biochimica Et Biophysica Acta-Molecular Cell Research (1998) 1405 (13), 67

36. Fu, Q., et al., Acta Biomater (2011) 7 (10), 3547

37. Weibel, G. L., and Ober, C. K., Microelectronic Engineering (2003) 65 (1-2), 145

38. Kerin, A. J., et al., Proceedings of the Institution of Mechanical Engineers Part H-Journal of Engineering in Medicine (1998) 212 (H4), 273

39. Repo, R. U., and Finlay, J. B., Journal of Bone and Joint Surgery-American Volume (1977) 59 (8), 1068

40. Jurvelin, J. S., et al., Journal of Biomechanics (1997) 30 (3), 235

41. Allen, J. L., et al., Molecular Biology of the Cell (2012) 23 (18), 3731

42. Li, S. W., et al., Lab Chip (2014) 14 (23), 4475

43. Little, C. J., et al., Tissue Eng. Part B (2011) 17 (4), 213

44. Farris, S., et al., Journal of Agricultural and Food Chemistry (2010) 58 (2), 998

45. Connell, L. S., et al., Polym. Chem. (2017) 8 (6), 1095

46. Woodfield, T. B., et al., Tissue Eng (2005) 11 (9-10), 1297 
47. Ren, L., et al., Biomaterials (2002) 23 (24), 4765

48. Edelsten, L., et al., Soft Matter (2010) 6 (20), 5206

49. Nuernberger, S., et al., Biomaterials (2011) 32 (4), 1032

50. Bhardwaj, T., et al., J Biomed Mater Res (2001) 57 (2), 190

51. Oh, S. H., et al., Biomaterials (2007) 28 (9), 1664

52. Defilippi, P., et al., Microscopy Research and Technique (1999) 47 (1), 67

53. Vondermark, K., et al., Nature (1977) 267 (5611), 531

54. Kino-Oka, M., et al., Tissue Eng. (2005) 11 (3-4), 597

55. Caron, M. M. J., et al., Osteoarthritis and Cartilage (2012) 20 (10), 1170

56. Cao, L., and Yang, B. B., Experimental cell research (1999) 246 (2), 527 